OPEN ACCESS

Edited by:

Brian D. Lanoil,

University of Alberta, Canada

Reviewed by:

John R. Spear,

Colorado School of Mines, USA

Julie L. Meyer,

University of Florida, USA

*Correspondence:

Stefan M. Sievert,

Biology Department, Woods Hole

Oceanographic Institution,

266 Woods Hole Road, Woods Hole,

MA 02543, USA

ssievert@whoi.edu

Specialty section:

This article was submitted to

Extreme Microbiology,

a section of the journal

Frontiers in Microbiology

Received: 13 May 2015

Accepted: 17 August 2015

Published: 10 September 2015

Citation:

Gulmann LK, Beaulieu SE, Shank TM,

Ding K, Seyfried WE and Sievert SM

(2015) Bacterial diversity

and successional patterns during

biofilm formation on freshly exposed

basalt surfaces at diffuse-flow

deep-sea vents.

Front. Microbiol. 6:901.

doi: 10.3389/fmicb.2015.00901

\section{Bacterial diversity and successional patterns during biofilm formation on freshly exposed basalt surfaces at diffuse-flow deep-sea vents}

\author{
Lara K. Gulmann', Stace E. Beaulieu', Timothy M. Shank', Kang Ding², \\ William E. Seyfried ${ }^{2}$ and Stefan M. Sievert ${ }^{1 *}$
}

${ }^{1}$ Biology Department, Woods Hole Oceanographic Institution, Woods Hole, MA, USA, ${ }^{2}$ Department of Earth Sciences, University of Minnesota, Minneapolis, MN, USA

Many deep-sea hydrothermal vent systems are regularly impacted by volcanic eruptions, leaving fresh basalt where abundant animal and microbial communities once thrived. After an eruption, microbial biofilms are often the first visible evidence of biotic recolonization. The present study is the first to investigate microbial colonization of newly exposed basalt surfaces in the context of vent fluid chemistry over an extended period of time (4-293 days) by deploying basalt blocks within an established diffuse-flow vent at the $9^{\circ} 50^{\prime} \mathrm{N}$ vent field on the East Pacific Rise. Additionally, samples obtained after a recent eruption at the same vent field allowed for comparison between experimental results and those from natural microbial re-colonization. Over 9 months, the community changed from being composed almost exclusively of Epsilonproteobacteria to a more diverse assemblage, corresponding with a potential expansion of metabolic capabilities. The process of biofilm formation appears to generate similar surface-associated communities within and across sites by selecting for a subset of fluid-associated microbes, via species sorting. Furthermore, the high incidence of shared operational taxonomic units over time and across different vent sites suggests that the microbial communities colonizing new surfaces at diffuse-flow vent sites might follow a predictable successional pattern.

Keywords: hydrothermal vents, colonization, species sorting, settlement, volcanic eruption, 16S rRNA, Epsilonproteobacteria, disturbance

\section{Introduction}

Microbes form the basis of the highly productive deep-sea hydrothermal vent ecosystems and serve as partners in symbiotic relationships or as food for fauna (Lutz and Kennish, 1993). These metabolically versatile chemosynthetic microbes harness chemical disequilibria created by the mixing of reduced hydrothermal fluids with oxygenated deep-sea water either above or below the seafloor (Baross and Hoffman, 1985; Jannasch and Mottl, 1985; Nakagawa and Takai, 2008). Vent fields are discrete regions separated by distances on the order of $100 \mathrm{~km}$ on the global mid-ocean ridge (MOR) system. Within a vent field, there are multiple sites of fluid venting, separated by meters to 100s of meters, including both focused-flow and diffuse-flow vent sites. Focused-flow sites are distinguished by characteristic black smokers, which are produced when undiluted, 
hot hydrothermal fluids (typically $350-400^{\circ} \mathrm{C}$ ) exit the seafloor. In contrast, at diffuse-flow sites, seawater mixes with hydrothermal fluid within the ocean crust, and is released as warm fluids (typically $<50^{\circ} \mathrm{C}$ ) through cracks in the seafloor.

Seafloor eruptions on intermediate- to fast-spreading MORs regularly destroy existing hydrothermal habitats, leave behind fresh basalt, and, by cracking and fissuring, create new hydrothermal emissions through openings in the basaltic seafloor (Haymon et al., 1993; Embley et al., 1995; Delaney et al., 1998; Shank et al., 1998; Huber et al., 2003; Tolstoy et al., 2006). Based on colonization experiments with artificial (non-basalt) substrates, newly exposed surfaces are colonized by microbes that form biofilms within days of exposure (Guezennec et al., 1998; Alain et al., 2004; Moussard et al., 2006). These microbial biofilms represent an important step in the primary colonization of deep-sea hydrothermal vents, as they allow microorganisms to maximize access to nutrients and energy sources in an environment typically characterized by high turbulence, and in turn support robust megafaunal communities. Initial microbial colonizers form the foundation of the vent ecosystem by playing a critical, yet poorly understood role in "conditioning" the substrate for settlement of metazoans, shaping the biological succession to follow. Microbial biofilms may facilitate the settlement and growth of particular microbial groups or act as faciliatory or inhibitory cues to metazoan larvae, thereby influencing the ultimate faunal community structure (Wieczorek and Todd, 1998; Hadfield, 2011; Wahl et al., 2012). Observational evidence suggests that larvae settle preferentially on surfaces precolonized by microbial biofilms (Rittschof et al., 1998; Taylor et al., 1999; Li et al., 2014). Additionally, biofilms may encourage immigration of mobile grazers (Shank et al., 1998).

Although researchers have observed biofilm formation on experimental substrates after only days (Guezennec et al., 1998; Moussard et al., 2006), little is known about the composition of microbial communities forming these early biofilms and how they change over time, as well as how biofilm communities on experimental substrates compare with those on natural substrates. Clarifying the progression of early microbial succession is key to understanding how diffuse flow vent communities establish and develop. The goal of this study is to examine how the composition of microbial communities change over time scales of a few days to 9 months on newly exposed surfaces at and adjacent to diffuseflow venting at the $9^{\circ} 50^{\prime} \mathrm{N}$ vent field on the East Pacific Rise (EPR; Figure 1). We hypothesized that the microbial communities colonizing new surfaces at diffuse-flow vents would: (1) follow a predictable successional pattern and (2) be similar among vent sites, but substantially different from non-vent habitats, as a result of species sorting from the fluid-associated source microbial community. To address these hypotheses, we compared the microbial succession both after an eruption ('natural re-colonization') and on basalt blocks placed within an established diffuse-flow vent community prior to the eruption ('experimental re-colonization').

\section{Materials and Methods}

\section{Sample Collection}

Basalt panels were deployed and recovered by DSV Alvin at Tica Vent on the EPR $\left(9^{\circ} 50.4^{\prime} \mathrm{N}, 104^{\circ} 17.5^{\prime} \mathrm{W}: 2513-\mathrm{m}\right.$ depth; Figure 1) during R/V Atlantis research cruises AT11-04 (2003/12/01 - 2003/12/19), 11-07 (2004/02/03 - 2004/02/19), 11 10 (2004/04/07 - 2004/04/24), 11-20 (2004/11/11 - 2004/11/24). Basalt panels were deployed either at a diffuse-flow vent site (Experiment site 1: $\sim 15^{\circ} \mathrm{C}$ ) or a nearby, non-vent site (Control site: $\sim 1.8^{\circ} \mathrm{C}$ ). Experiment site 1 was located within a thriving patch of tubeworms (Riftia pachyptila) and mussels (Bathymodiolus thermophilus). The Control site was located 2.5$\mathrm{m}$ from the experimental site, $\sim 1 / 2-\mathrm{m}$ from mussels marking the edge of the colonized vent (Supplementary Figures S1A-C). These panels are considered 'pre-eruption' samples because they were collected 19-28 months before the 2005/2006 EPR eruption (Tolstoy et al., 2006; Cowen et al., 2007; Soule et al., 2007).

For the purpose of comparison with our experimental results, one post-eruption native basalt biofilm sample (hereafter referred to as 'native Basalt') was collected from Tamtown $\left(9^{\circ} 50.3^{\prime}\right.$ $\mathrm{N}, 104^{\circ} 17.4^{\prime} \mathrm{W}$ : $2503-\mathrm{m}$ depth; $\sim 0.58 \mathrm{~km}$ from Tica Vent: Figure 1), during the RESET06 cruise (AT15-06, 2006/06/25 2006/07/01). This EPR volcanic eruption was dated around the end of 2005/early 2006 (Rubin et al., 2006; Tolstoy et al., 2006; Soule et al., 2007), indicating that the Tamtown Basalt collected was $\sim 5-8$ months-old. In addition, one biofilm sample (hereafter referred to as 'Trap') was collected at this location from a cylindrical stainless steel collection device placed in the outflow of an active diffuse flow vent for 4 days.

Basalt panels $(10.2 \mathrm{~cm} \times 10.2 \mathrm{~cm} \times 2.5 \mathrm{~cm})$ were constructed of basalt collected in the area of $9^{\circ} \mathrm{N}$ on the EPR (Supplementary Figure S1D). Before deployment, all panels were sealed in aluminum foil and autoclaved. Each panel was deployed from and recovered into an ethanol-wiped biobox mounted on Alvin's basket, filled prior to the dive with either $0.2-\mu \mathrm{m}$ filtered seawater or double-distilled water to prevent contamination with surface seawater (as were the native Basalt and Trap samples). All subsequent handling of the basalt panels was with sterilized gloves or tools. Control and experimental basalt panels were exposed for five time intervals: 4-, 9-, 13-, 76-days, and 9-mos [283-days (control) and 293-days (experimental)]. One panel was lost (76-days, control), leaving a total of nine panels for analysis, in addition to the native Basalt and Trap samples.

\section{Chemical Measurements}

For additional habitat characterization, we attached a timeseries temperature sensor (VEMCO) directly to one of the basalt panels at both the experimental (attached to Day 293E) and control sites (attached to Day 13C; Supplementary Figure S2) and deployed an in situ chemical sensor at Experiment site 1, to monitor dissolved $\mathrm{H}_{2} \mathrm{~S}$, Eh (oxidation-reduction potential), and temperature (Supplementary Figures S3A-C). The VEMCO temperature sensor sampled every $5 \mathrm{~s}$ and recorded temperatures for 293 days at Experiment site 1 and for 13 days at the control site. The chemical sensors were implanted amongst 


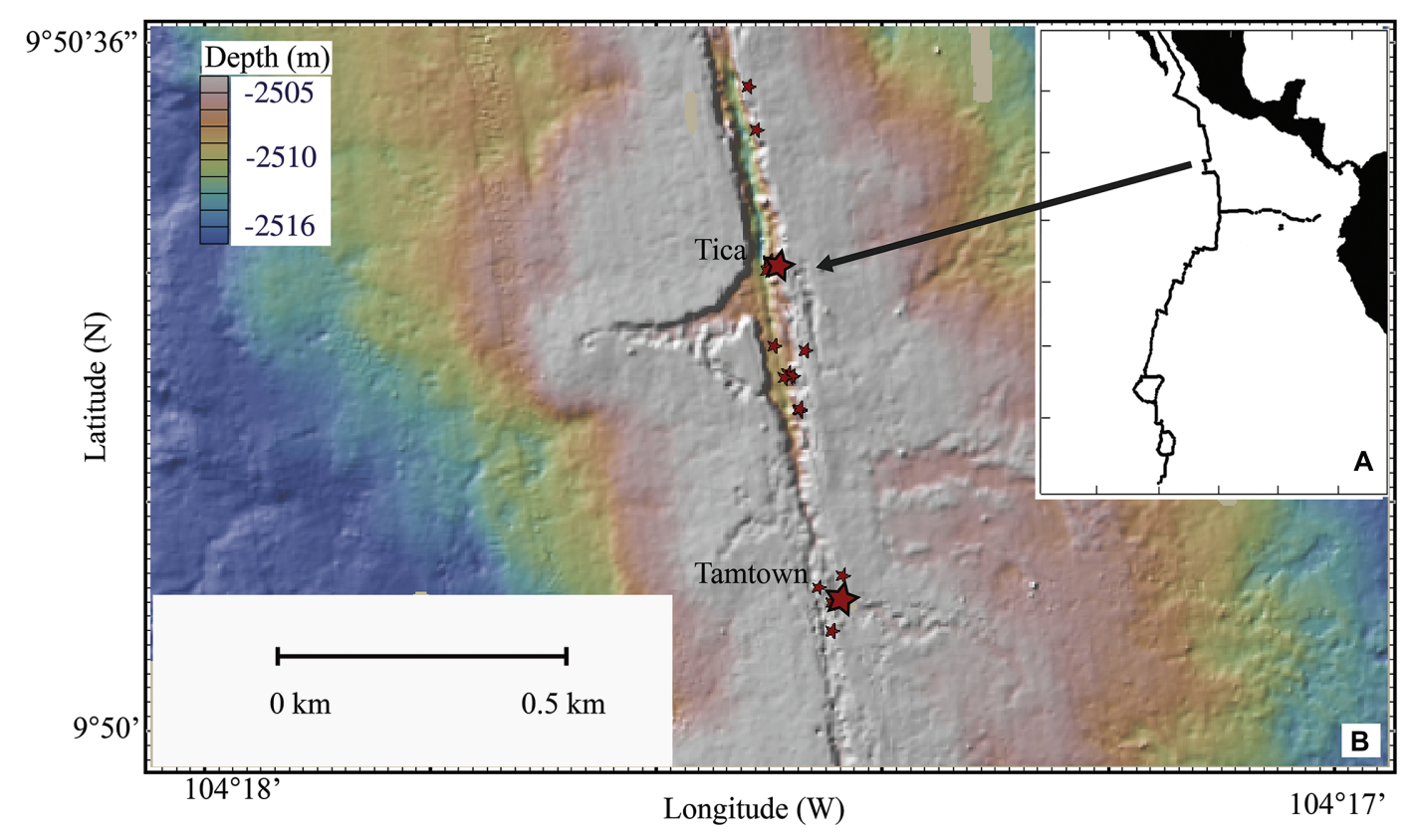

FIGURE 1 | Map of the East Pacific Rise. (A) Location of the EPR. (B) Topographical map of sampling sites. Larger stars indicate Tica (site for basalt panels) and Tamtown (site for native Basalt) locations, smaller stars indicate locations of other vent sites.

the tubeworms, using real-time temperature via an inductively coupled communication link (ICL) as a guide for placement in vent fluids $\left(\sim 11^{\circ} \mathrm{C}\right.$ for Experiment site 1$)$. The chemical sensors were deployed for 13 days and sampled every 5-s. Furthermore, the chemical sensors were calibrated before and after deployment.

\section{Molecular Techniques DNA Extraction}

Environmental DNA was extracted from the basalt panel surfaces using a large-volume CTAB (hexadecyltrimethylammonium bromide) extraction. Individual basalt panels were placed into warmed $\left(55^{\circ} \mathrm{C}\right)$ DNA extraction buffer, composed of $100 \mathrm{mM}$ Tris-HCl ( $\mathrm{pH} 8.0$ ), $20 \mathrm{mM}$ EDTA ( $\mathrm{pH} 8.0$ ), $1.4 \mathrm{M} \mathrm{NaCl}$ and $2 \% \mathrm{CTAB}$, with mercaptoethanol added to $0.2 \%$ via syringe filter. Filter-sterilized Proteinase K solution and sodium dodecyl sulfate (SDS) solution were added to final concentrations of $0.1 \mathrm{mg} / \mathrm{mL}$ and $0.65 \%$ respectively. Covered by this extraction solution, each block was agitated on a shaker table for $2 \mathrm{~h}$ at $55^{\circ} \mathrm{C}$. Biofilm removal was confirmed by inspection of the extracted blocks under a dissecting microscope. DNA was extracted from this solution with an equivalent volume of phenol:chloroform:isoamyl alcohol (25:24:1, pH 8.0), followed by an equivalent volume of chloroform:isoamyl alcohol (24:1). To precipitate the DNA, 0.1 volume of $3 \mathrm{M}$ sodium acetate and 2.5 volumes of cold $100 \%$ ethanol were added, then placed into $-20^{\circ} \mathrm{C}$ for $3 \mathrm{~h}$ before centrifuging at $10,000 \times g$ for $15 \mathrm{~min}$. After decanting the supernatant, the pellets were covered with cold $70 \%$ ethanol and centrifuged at $16,000 \times g$ for $5 \mathrm{~min}$. The ethanol was pipetted off and the pellets were dried. Isolated DNA was resuspended in 50-200 $\mu \mathrm{l}$ sterile water and kept at $-80^{\circ} \mathrm{C}$ until use. Environmental DNA from Trap and native Basalt samples was extracted with using the Ultraclean Soil DNA extraction kit (MoBio Laboratories).

\section{Clone Library Construction and Full-Length 16S rRNA Sequencing}

The 16S rRNA region of environmental DNA was amplified (27F, 1492R primers) and replicates of 10 PCR amplifications (15 cycles each) were combined, precipitated using a QIAquick PCR purification kit (Qiagen), resuspended in $35 \mu \mathrm{l}$ of sterile water and purified using the QIAquick gel extraction kit (Qiagen). Replicate PCR reactions were combined in order to minimize PCR bias (Polz and Cavanaugh, 1998) and only 15 cycles were used to decrease the formation of chimeric sequences and Taq error. The combined products were then reamplified with five additional PCR cycles to minimize the formation of heteroduplex molecules (Thompson et al., 2002) and purified using a QIAquick gel extraction kit (Qiagen).

Purified PCR products of the 16S rRNA gene were cloned with the Strataclone PCR cloning kit (Stratagene) for sequencing. Nearly complete, double-stranded sequences of 16S rRNA genes $(\sim 1,475 \mathrm{bp})$ were sequenced on a 96-capillary $3730 \mathrm{xl}$ DNA analyzer (Applied Biosystems) with primers M13F and M13R. For all libraries, single strand sequences were grouped by 97\% similarity with the program Sequencher (version 4.1.2, Applied Biosystems) and one representative of each group was selected to sequence both forward and reverse strands. These groupings were designated operational taxonomic units (OTUs). Sequences were tested for the presence of chimeras with the program Mallard (Ashelford et al., 2006) and with 
the Bellerophon server (Huber et al., 2004). The full-length $16 \mathrm{~S}$ rRNA sequences reported in this paper have been deposited in the GenBank database under accession numbers KT257735KT257859.

\section{Pyrosequencing of V4 16S rRNA Tags}

Primers $517 \mathrm{~F}$ and $806 \mathrm{R}$ were used to target the V4 region of the 16S rRNA gene (Caporaso et al., 2010). For multiplex sequencing, eight forward primers were synthesized (Eurofin), each with a different tag. PCR reactions (50 $\mu$ l volume) contained $250 \mathrm{nM}$ of each of forward and reverse primers, $5 \mathrm{ng}$ of template DNA and were performed using Picomaxx taq polymerase (Invitrogen, Carlsbad, CA, USA) using the thermal profile $95^{\circ} \mathrm{C}$ for $2 \mathrm{~min}$ followed by 25 cycles of denaturation at $94^{\circ} \mathrm{C}$ for $15 \mathrm{~s}$, primer annealing at $61^{\circ} \mathrm{C}$ and extension at $72^{\circ} \mathrm{C}$ for $45 \mathrm{~s}$, with final extension of $72^{\circ} \mathrm{C}$ for $3 \mathrm{~min}$. Amplicons were sequenced at EnGenCore, now Selah Genomics, using 454 FLX chemistry. Raw sequences were processed with QIIME 1.8.0 (Caporaso et al., 2010). Sequences were excluded from analysis if they had a mean quality score $<25$, were either $<200$ or $>500 \mathrm{bp}$ in length, contained ambiguous nucleotides or had any mismatches in the forward and reverse primers. The sequences were assigned to individual samples by their adapter tags and the 16S rRNA primers were removed prior to analysis. The resulting data sets contained $254 \mathrm{bp}$ of the bacterial V4 region. Potential chimeras were identified and removed using ChimeraSlayer. Trimmed sequences were then classified with RDP classifier. OTUs were clustered at $97 \%$ similarity based on a distance matrix generated with the program QIIME. SFF files were assigned GenBank SRA Bioproject number PRJNA288972.

\section{Phylogenetic and Statistical Analysis}

Phylogenetic trees were constructed from aligned clone sequences and closely related environmental clones and cultures using the neighbor-joining algorithm in the MEGA6 software package (Tamura et al., 2013) and the Silva release 119 database. Tag sequences that were identical to a clone sequence were identified in trees. Bootstrap values were calculated using MEGA6. Alpha and beta diversity estimates were calculated using QIIME. After trimming each sample to an equal number of tags, bacterial diversity was estimated with $\mathrm{N}_{\text {obs }}$ (observed richness), Chaol (non-parametric richness estimator), nonparametric (np) Shannon diversity index, Simpson Evenness and Equitability. Structure of the pyrosequenced microbial communities was compared with two different methods. Principal coordinate analysis (PCoA) maps the samples on a set of orthogonal axes in order to explain the maximum amount of variation by the first coordinate and the second largest amount of variation by the second coordinate based on weighted UniFrac values (Lozupone et al., 2010). The UPGMA (unweighted pair group method with arithmetic mean) distance tree is based on a hierarchical clustering in which topological relationships are identified in order of similarity. The robustness of the UPGMA clusters was tested with jackknife analysis, based on 100 randomized subsamples.

\section{Results}

\section{Habitat Chemistry}

Based on the VEMCO temperature sensors, temperature at Experiment site 1 ranged from 2.6 to $21.4^{\circ} \mathrm{C}$ (average $10.7^{\circ} \mathrm{C}$ ) over the course of the experiment, while temperatures at the Control site ranged from 1.8 to $3.0^{\circ} \mathrm{C}$ (average $2.3^{\circ} \mathrm{C}$ ) over the first 13 days of the experiment (Supplementary Figure S2). The temperature recorded by the in situ chemical sensor (Supplementary Figure S3A), ranged from 8.7 to $20.9^{\circ} \mathrm{C}$ (average $17.2^{\circ} \mathrm{C}$ ), but only measured for the first 13 days of the experiment. Immediately following deployment, temperature increased from $\sim 9$ to $20^{\circ} \mathrm{C}$, but then subsequently decreased and increased in a pattern suggestive of tidal influences (Supplementary Figure S3A). Total dissolved sulfide and Eh (Supplementary Figures S3B,C) were initially at or below detection, but increased, or became more reducing subsequently. After $\sim 1-2$ days, data reveal steady state redox conditions with small-scale changes that likely reflect temperature variability, although the cause of this is difficult to quantify unambiguously. In general, the dissolved sulfide concentrations ranged from 10 to $100 \mu \mathrm{M}$ and the mean value of dissolved sulfide was in the range of $20-30 \mu \mathrm{M}$.

\section{Phylogenetic Diversity}

We studied bacterial diversity on basalt surfaces at diffuse flow vent sites (Figure 1) using a combination of full-length Sanger sequencing of $16 \mathrm{~S}$ rRNA clones (full-length clones) and 454-pyrosequencing of the hypervariable $\mathrm{V} 4$ region of $16 \mathrm{~S}$ rRNA (V4 tags). While the use of V4 tags allowed a more extensive assessment of microbial diversity of the samples, the generation of full-length sequences provides a means to perform phylogenetic analyses and to verify the taxonomic assignments of the most dominant groups. Sample 76C was not recovered and sample 4C had insufficient DNA for molecular analysis. Using the same DNA extracts, we amplified the V4 region of the $16 \mathrm{~S}$ rRNA gene for pyrosequencing of eight samples (all samples amplified for clone libraries except day $4 \mathrm{E}$ and Trap), generating over 60,500 reads, with 23,155 reads passing through the quality control criteria. Both methods (Sanger sequencing and 454-pyrosequencing) detected the same overall pattern of community composition (Figure 2) and changes with time (Figures 3 and 4). Similarly, other environmental studies of hydrothermal vent habitats have indicated a good correspondence between clone libraries and tag pyrosequencing approaches (Sylvan et al., 2012b; Forget and Juniper, 2013). Multiple attempts to amplify archaeal 16 S rRNA using archaeal specific primers were unsuccessful. Although other studies have recovered archaeal DNA from high temperature vents (Byrne et al., 2009; Opatkiewicz et al., 2009), other researchers have also failed to amplify Archaea from lower temperature diffuse flow vents (Forget et al., 2010; Forget and Juniper, 2013).

According to rarefaction data and diversity indices based on the 454 tag sequences (Figure 5; Table 1A), the 9months experimental panel hosted the most diverse microbial community. The 9-months control has a microbial community 

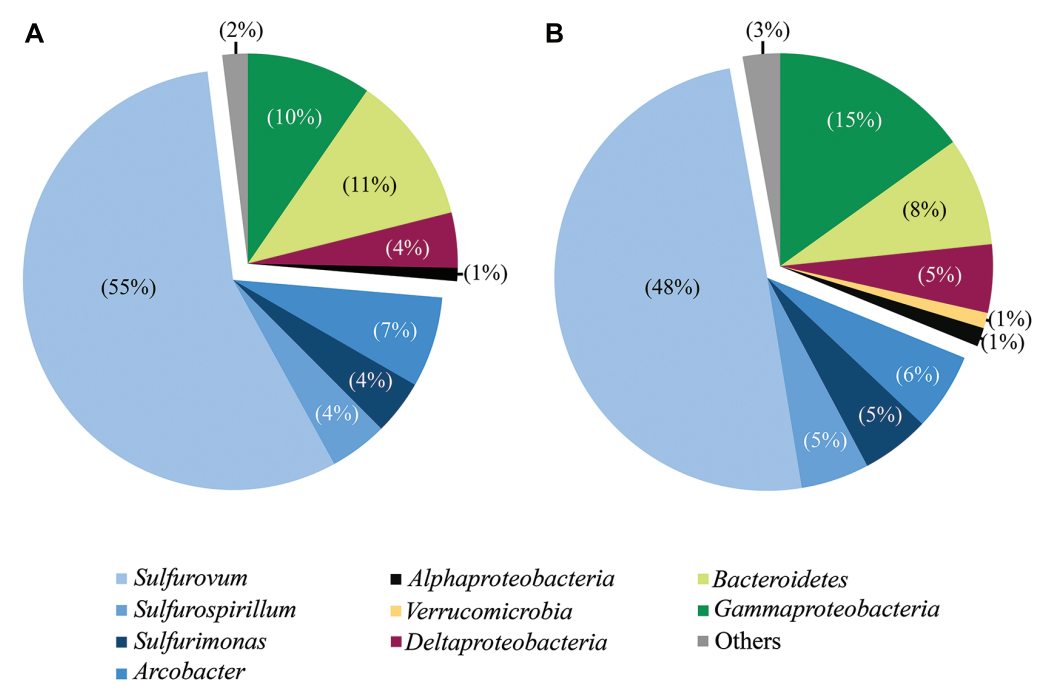

Bacteroidetes

- Gammaproteobacteria

Others

FIGURE 2 | Taxonomic breakdown and relative abundance for combined tag (A) and clone (B) sequences. All libraries analyzed by both methodologies are grouped (all libraries except Trap and day 4E).

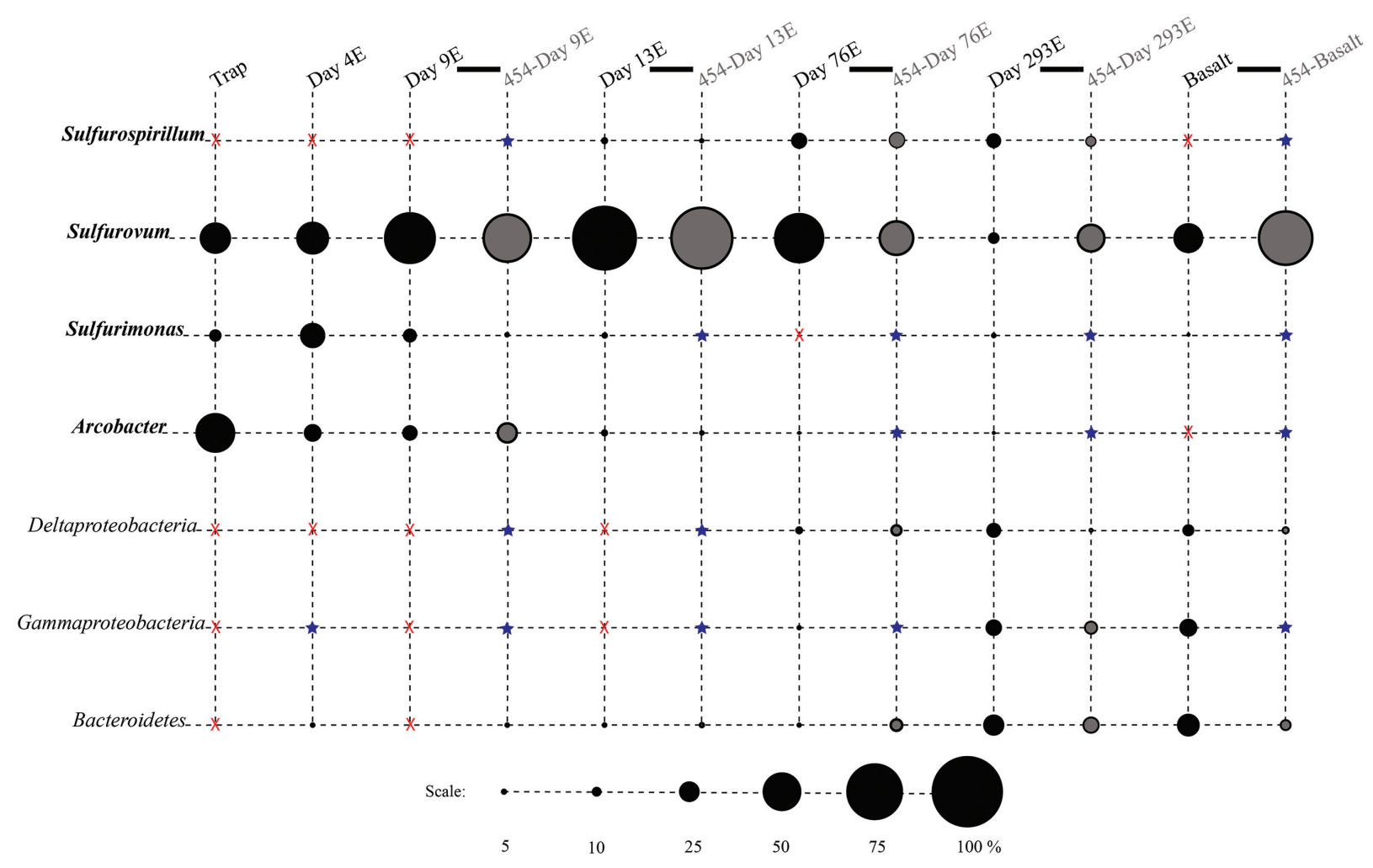

FIGURE 3 | Relative proportions of abundant phylogenetic groups for experimental treatments and Basalt. Pyrosequenced samples are labeled as 454-sample name (gray shading). All other samples were sequenced with the Sanger method (black shading). Epsilonproteobacterial groups are labeled in bold italics. Groups in which no clones/tags were sequenced are indicated with a red 'X.' Groups which were detected at or below $2 \%$ are indicated with a blue star.

only slightly less diverse than the corresponding experimental time point, and comprised the largest number of singletons (62), as well as the second highest calculations for Chaol and
Shannon indices (based on 454 tag sequence analysis). In general, the early time points ( $<2$ weeks exposure, both control and experimental) had the least diverse communities and diversity 


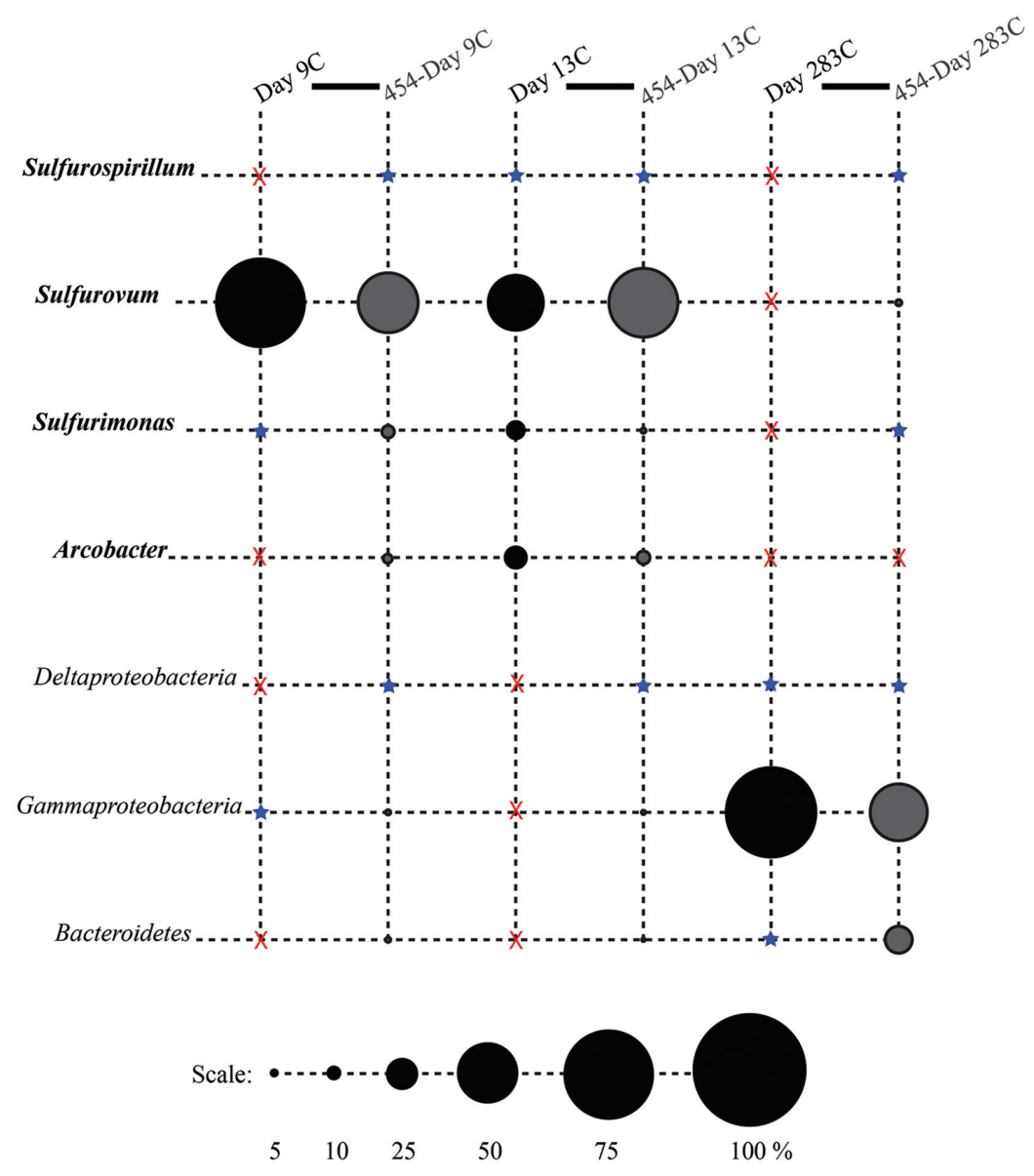

FIGURE 4 | Relative proportions of abundant phylogenetic groups for control treatments. Pyrosequenced samples are labeled as 454-sample name (gray shading). All other samples were sequenced with the Sanger method (black shading). Epsilonproteobacterial groups are labeled in bold italics. Groups in which no clones/tags were sequenced are indicated with a red ' $X$.' Groups which were detected at or below $2 \%$ are indicated with a blue star.

increased with age. However day 9C was an exception, with its relatively large number of singletons (58) and relatively high Chaol value (144). The estimated diversity of the native Basalt sample falls in between early and late time-points, as confirmed with the Shannon index, which incorporates both the richness and evenness of the community. The calculated Simpson Evenness and Shannon indices both indicate that the experimental communities become more even as they age (Table 1A). In comparing the two methods, both libraries found $293 \mathrm{E}$ to be the most diverse sample, and both found $9 \mathrm{E}$ to be the least diverse sample. Interestingly, the tag library revealed greater diversity of two control samples, 283C and 9C (Tables 1A,B).

\section{Comparison of Bacterial Communities Composition of Libraries}

Phylotypes from three subdivisions of Proteobacteria, i.e., Gamma-, Epsilon-, and Deltaproteobacteria, as well as Bacteroidetes constituted the majority of sequences in all samples (Figures 2A,B, 3, and 4). The overall results indicate a shift, over a period of months, from a community dominated by
Epsilonproteobacteria, to a more diverse community including Bacteroidetes, Gamma-, and Deltaproteobacteria, among others (Figures 3 and 4).

Surprisingly, the composition of the control and experimental libraries were highly similar for the first 13 days, and only diverged sometime thereafter. In particular, days 9E, 9C, and 13C group in their own branch of the UPGMA tree and form a cluster in the weighted PCoA plot (Figures 6A,B). Libraries from days 76E and 293E formed a separate group, while bacterial communities found on the native Basalt and 13E shared similarities with both of these clusters. Both measures indicate that the bacterial community found associated with panel $283 \mathrm{C}$ is the most disparate from all other libraries (Figures 6A,B).

Among the Epsilonproteobacteria, $>90 \%$ of tag OTUs were detected in multiple panel samples. Of the total 132 OTUs identified for the native Basalt sample, only seven OTUs were not present in the experimental panels and these OTUs comprise $<2 \%$ of the total tags for the native Basalt sample (Supplementary Tables S1A-D and 2A-D). Within the Epsilonproteobacteria, 94\% of the OTUs detected for the native Basalt sample were also found on the experimental panels, $0.58 \mathrm{~km}$ apart [Tamtown 


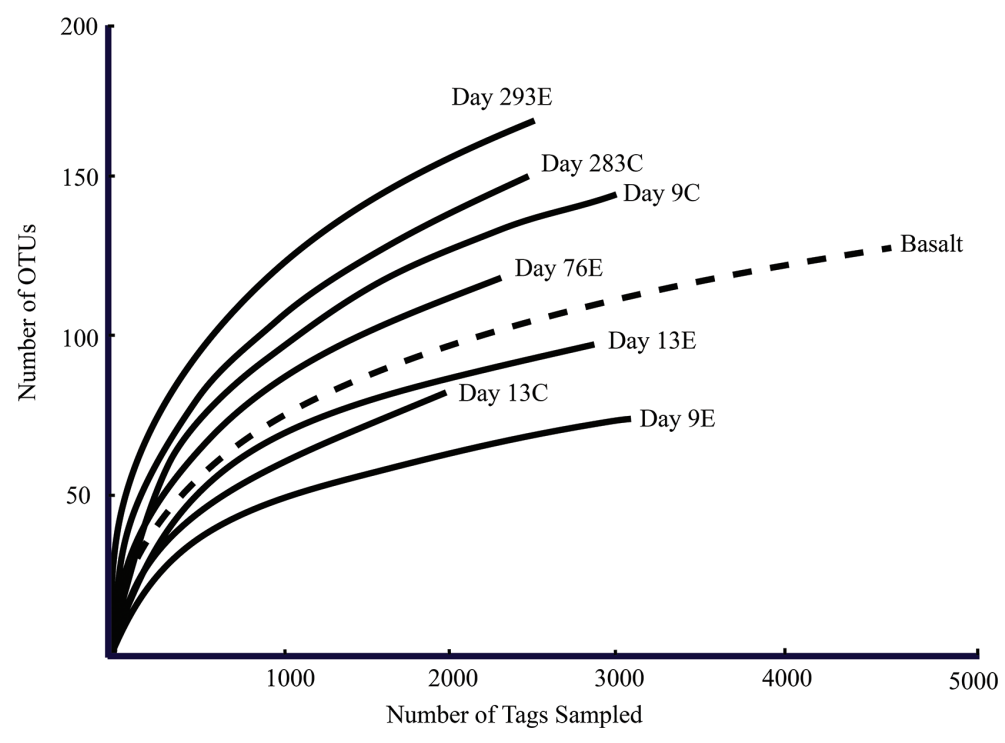

FIGURE 5 | Rarefaction curves for panel samples (Tica vent - solid line) and Basalt sample (Tamtown vent - dashed line). OTUs were calculated with a cutoff of $3 \%$.

(native Basalt) and Tica vent (panel samples)]. From the earliest timepoints, $>38 \%$ of the Epsilonproteobacterial OTUs found at day $4 \mathrm{E}$ (Tica vent) were also detected in the Trap library (Tamtown; Supplementary Table S2A).

\section{Epsilonproteobacteria}

Up to day 76, Epsilonproteobacteria accounted for the majority of tags and clones in all libraries (65-95\% tags; $82-96 \%$ clones). The Trap library was exclusively comprised of Epsilonproteobacteria

TABLE 1A | Diversity estimates from 16S rRNA amplicon libraries: 454 tag sequences.

\begin{tabular}{|c|c|c|c|c|c|c|c|}
\hline Sample & Reads & $\mathbf{N}_{\text {obs }}$ & Singletons & Chao1* & Shannon & Simpson evenness & Equitability \\
\hline Day 9E & 3148 & 74 & 24 & $109(86-170)$ & 3.21 & 0.017 & 0.52 \\
\hline Day 13E & 2892 & 98 & 30 & $123(107-160)$ & 3.96 & 0.012 & 0.60 \\
\hline Day 76E & 2309 & 118 & 45 & $201(155-301)$ & 4.49 & 0.009 & 0.65 \\
\hline Day 293E & 2568 & 168 & 54 & 230 (199-292) & 5.31 & 0.006 & 0.72 \\
\hline Basalt & 4732 & 132 & 43 & $188(158-255)$ & 3.69 & 0.010 & 0.52 \\
\hline Day 9C & 2993 & 144 & 58 & $216(181-285)$ & 4.05 & 0.008 & 0.56 \\
\hline Day 13C & 2003 & 82 & 39 & $156(114-256)$ & 3.31 & 0.015 & 0.52 \\
\hline Day 283C & 2510 & 151 & 62 & 224 (189-290) & 4.63 & 0.007 & 0.64 \\
\hline
\end{tabular}

* The ranges shown are 95\% confidence intervals.

TABLE 1B | Diversity estimates from 16S rRNA amplicon libraries: clone sequences.

\begin{tabular}{|c|c|c|c|c|c|c|c|}
\hline Sample & Clones & $\mathbf{N}_{\text {obs }}$ & Singletons & Chao1* & Shannon & Simpson evenness & Equitability \\
\hline Trap & 63 & 13 & 6 & $20(14-55)$ & 2.52 & 0.113 & 0.70 \\
\hline Day 4E & 55 & 20 & 9 & $26(21-47)$ & 3.75 & 0.056 & 0.87 \\
\hline Day 9E & 56 & 13 & 7 & $24(15-67)$ & 2.91 & 0.094 & 0.79 \\
\hline Day $13 E$ & 50 & 17 & 8 & $26(19-62)$ & 5.10 & 0.066 & 0.88 \\
\hline Day $76 \mathrm{E}$ & 59 & 25 & 15 & $60(35-151)$ & 3.59 & 0.044 & 0.87 \\
\hline Day 293E & 53 & 38 & 27 & $82(54-155)$ & 4.05 & 0.027 & 0.97 \\
\hline Basalt & 64 & 27 & 19 & $70(40-166)$ & 3.24 & 0.041 & 0.83 \\
\hline Day 9C & 51 & 12 & 7 & $17(13-40)$ & 2.97 & 0.154 & 0.56 \\
\hline Day $13 C$ & 46 & 15 & 8 & $24(17-60)$ & 3.97 & 0.079 & 0.83 \\
\hline Day 283C & 57 & 15 & 9 & 27 (18-69) & 2.01 & 0.082 & 0.76 \\
\hline
\end{tabular}

* The ranges shown are 95\% confidence intervals. 


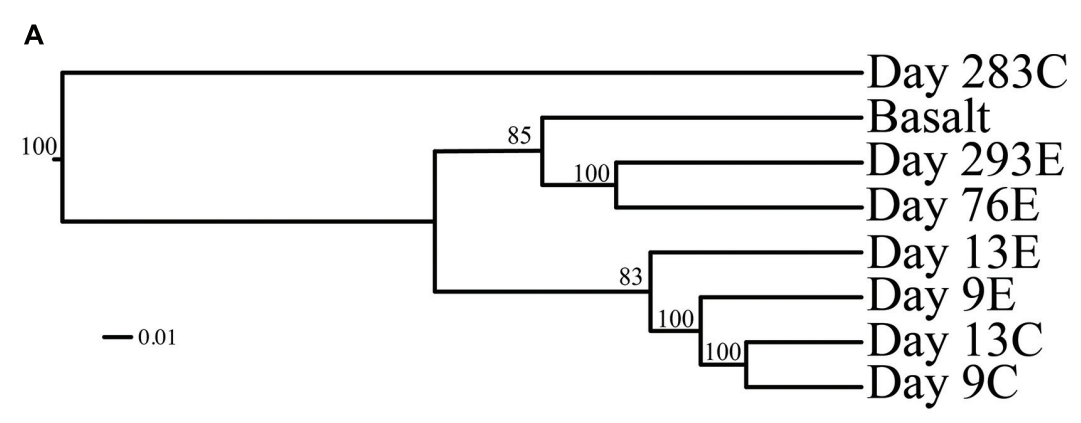

B

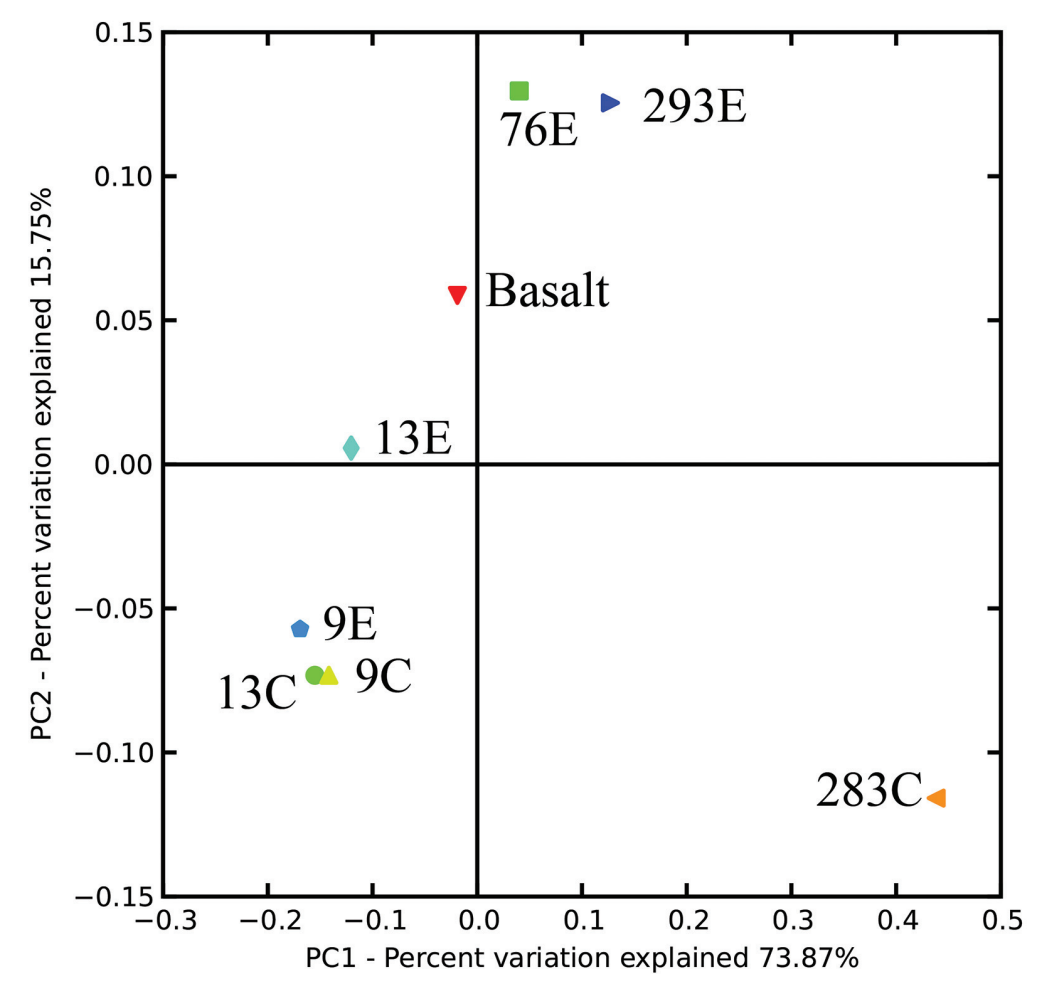

FIGURE 6 | (A) Unweighted pair group method with arithmetic mean (UPGMA) distance tree of the 454 bacterial community structure. Jacknife support is indicated at the nodes. (B) PCoA plots of all 454 libraries with weighted UniFrac. The first two principal coordinate axes in PCoA and percentages of variation that they explain are shown.

and every time point for the first 2 weeks contained $>90 \%$ Epsilonproteobacterial clones and tags. In particular, the genus Arcobacter was prevalent until day 13, comprising up to $25 \%$ of all tags (day 9E) and $>50 \%$ of all clones (Trap; Figure 3 ). But after 2 weeks, the proportion of Arcobacter decreased and never comprised more than $2.5 \%$ of the total tags or clones. No Arcobacter clones/tags were found for 283C. For the native Basalt sample, no Arcobacter clones were detected and few 454 tags were recovered (20 tags, <0.1\%). Even though Arcobacter comprise 7 and 6\% of all tags and clones, and over a quarter of all tag sequences for day $9 \mathrm{E}$, these sequences were all grouped within only a few OTUs. Only seven Arcobacter tag OTUs were detected and over $84 \%$ of all Arcobacter tags belonged to a single OTU (Supplementary Table S1A). This OTU
(Clone.101:Tag.342) shares 99\% sequence identity with a clone (JN873988) collected from a Trap $30 \mathrm{~m}$ southwest of vent Bio9 at the EPR, which collected hydrothermal plume particles (Figure 7; Supplementary Figure S4A; Sylvan et al., 2012a).

Within the Epsilonproteobacteria, OTUs belonging to the Sulfurovum genus constituted the dominant fraction of tags and clones across all time points except the 9-months experimental and control (293E, 283C) and Trap sample (Figures 3 and 4). Many Sulfurovum-related tags/clones were most closely related to sequences previously identified from hydrothermal vent environments, and in particular to clones found at vent sites also colonized by vent fauna (Huber et al., 2006; Goffredi et al., 2008; Sylvan et al., 2012b; Forget and Juniper, 2013; Figure 7). The most abundant sequence (Clone.32 Tag.264) comprised 16\% of all tag 


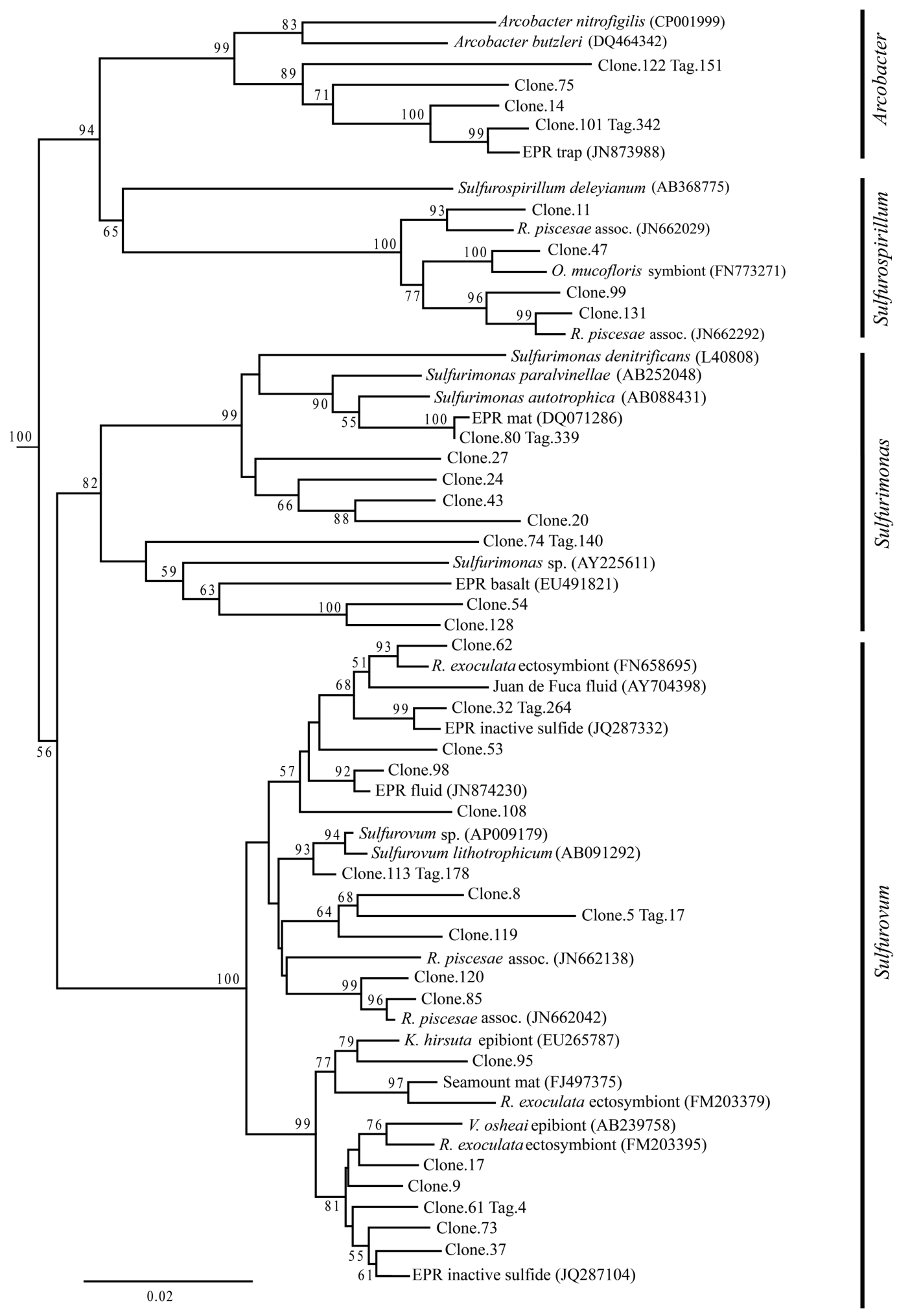

FIGURE 7 | Epsilonproteobacteria phylogenetic tree. Neighbor-joining trees were constructed from aligned, full-length clone 16S rRNA sequences of OTUs detected more than once, based on 1,197 homologous positions filtered by base frequency (50\%) using MEGA6. Tag sequences that were identical to a clone sequence were identified. Bootstrap values were calculated in MEGA6, and nodes with $>50 \%$ support, based on 1,000 replicates are displayed. Hydrogenobacter hydrogenophilus (Z30242) and Thermosulfidicus takaii (AB282756) were used as outgroups. 
sequences and $19 \%$ of all clone sequences and is $>99 \%$ similar to a Sulfurovum-like sequence from an extinct sulfide (JQ287332; Sylvan et al., 2012b; Supplementary Figure S4A). Many of the identified tags/clones were only distantly related to any cultured representatives.

Sulfurimonas-related tags were also more common in early time points, comprising between 2 and 5\% of all tags for days 9 and 13 (Figures 3 and 4). Sulfurimonas tags make up less than $1 \%$ of all tags for 293E $(0.9 \%)$ and $283 \mathrm{C}(0.4 \%)$ and only $1.4 \%$ of all native Basalt tags. In clone libraries, Sulfurimonasrelated sequences accounted for $27 \%$ of all clones of the earliest time point (day $4 \mathrm{E}$ ) and subsequently decreased. When samples were grouped (all except Trap and day 4E), Sulfurimonas-related sequences comprised $5 \%$ of the total for clone libraries and $4 \%$ of the total for 454 tag libraries (Figures 2A,B). One OTU (Clone.80 Tag.339) was closely related to Sulfurimonas paralvinellae ( $>97 \%$ similarity; Figure 7), a mesophilic, facultatively anaerobic, strictly chemolithoautotrophic epsilonproteobacterium using the oxidation of $\mathrm{H}_{2}$ or reduced sulfur compounds as an energy source (Takai et al., 2006).

Sulfurospirillum-related tags were first detected in low abundances at day 9 (9C and 9E $<1 \%$ total; Figures 3 and 4 ). Relative abundances peaked on day $76 \mathrm{E}$, where they comprised $19 \%$ of all tags for that sample, and were also found at day 293E (321 tags, 12\% total). Clones related to Sulfurospirillum species were not detected until day 13 . Initially, clones belonging to Sulfurospirillum comprised only $4 \%$ of the library for $13 \mathrm{E}$, but made up $17 \%$ of all clones by time points $76 \mathrm{E}$ and $293 \mathrm{E}$, respectively. Up to this point all described species of the genus Sulfurospirillum are heterotrophs capable of using sulfur as an electron acceptor (Campbell et al., 2006).

\section{Gamma- and Deltaproteobacteria and Bacteroidetes}

After 9 months of exposure, the experimental panel library comprised a mixture of Bacteroidetes, Epsilon- and Gammaproteobacteria, and the control library was dominated by Gammaproteobacteria ( $>57 \%$ of all tags and $>90 \%$ of all clones in the control library (Figure 4). Pyrosequencing results recovered a high proportion of Thiotrichales tags (42\%) distributed among 13 OTUs. Within the Thiotrichales, Clone.1 is $>97 \%$ similar to clones previously identified on an off-axis EPR basalt, and implicated in basalt alteration reactions (GenBank accession number EU491733; Figure 8; Santelli et al., 2009). Interestingly, only one Chromatiales OTU tag was detected, but it constituted $12 \%$ of all gammaproteobacterial tags and is particularly abundant in the 9-months experimental samples (9\% of all 293E tags). This OTU (Clone.72 Tag.92) shares 99\% sequence identity with the endosymbiont of Tevnia jerichonana (Figure 8; Supplementary Figure S4B). The typical deep-sea psychrophilic and barophilic genus Colwellia was detected in low abundance $(<3 \%)$ in all tag samples except the native Basalt, 76 E and 293E (Supplementary Figure S4B; Supplementary Table S1B).

Bacteroidetes were found in all pyrosequencing libraries, and comprised $\sim 1$-quarter of all tags for both the 9-months experimental and control panels (Figures 3 and 4). Most tag sequences were related to the Flavobacteriales, an order that, based on cultures, is comprised of heterotrophic bacteria that have a range of physiologies and are found in diverse ecological niches (Kirchman, 2002). Pyrosequencing libraries comprised a relatively high number of Bacteroidetes OTUs (108 OTUs across all samples), but most were detected at low abundance (i.e., only seven OTUs with $>50$ tags/sample).

Until day 76, Deltaproteobacteria were not detected by clone libraries and comprised $<1 \%$ of the tag sequences (Figures 3 and 4). At 293 days, $5 \%$ of the tags on the experimental panel belonged to the Deltaproteobacteria, but higher proportions were found on the native Basalt (9\%) and day 76E (14\%) panel. Over half the Deltaproteobacteria clones (59\%) and tags (71\%) sequenced belonged to the order Desulfobacterales, and most of these belonged to the sulfur-disproportionating genus Desulfocapsa. For individual samples, the greatest proportion of Desulfocapsa tags were detected on native Basalt (8\%) and day 76E (9\%; Supplementary Table S1D).

\section{Discussion}

\section{Biofilm Formation and Microbial Succession}

From our results it is clear that diffuse-flow vent microbial communities evolve over short time scales (from a few days to 9 months) from being composed almost exclusively of Epsilonproteobacteria (namely, Sulfurovum and Arcobacter) to a more diverse assemblage of Epsilon-, Gamma-, Deltaproteobacteria and Bacteroidetes. In contrast, sites outside of the diffuse venting region developed into a community dominated by Gammaproteobacteria and Bacteroidetes, albeit of similarly high diversity. Surprisingly, the compositions of the microbial communities on the control and experimental basalt panels were highly similar for the first 13 days, and only diverged sometime thereafter. This is despite the fact that the temperature did not show a hydrothermal signal at the Control site. Fluidassociated organisms were likely transported away from the vent site by currents, providing a constant means for microbes to be delivered to the Control site, only $2.5 \mathrm{~m}$ away from the experimental site. While chemoautotrophic vent bacteria were able to settle on the control panels, they were probably not able to grow to appreciable numbers, preventing the formation of extensive biofilms. In addition to visual observations, this was apparent in the much lower DNA yield from the control panels compared to the experimental panels, such that the earliest control time point (day 4C) did not have sufficient DNA for PCR amplification. Over time, bacteria present in the ambient deep-sea water (i.e., Alteromonadales) as well as bacteria able to extract energy from fluid-associated minerals or organic matter (Templeton et al., 2009) or from the basalt itself (Santelli et al., 2008, 2009), colonized the control panels, resulting in a community distinct from the experimental basalt surfaces. For the purposes of this paper, the 9-months time points allow a comparison between experimental and control settings, while the early libraries allow insights into which bacterial groups are early colonists on freshly exposed basalt surfaces in proximity to diffuse-flow venting. 


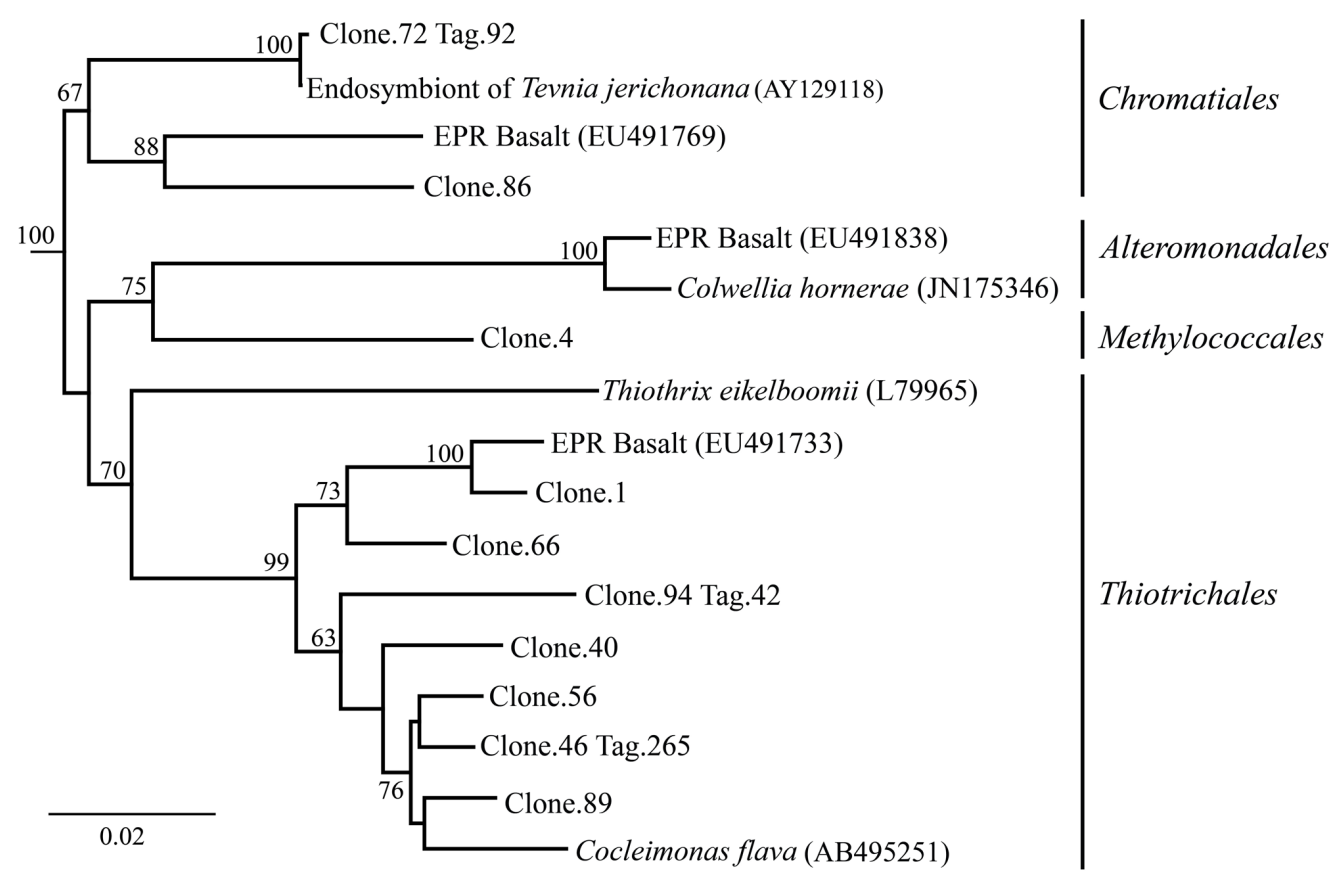

FIGURE 8 | Gammaproteobacteria phylogenetic tree. Neighbor-joining trees were constructed from aligned, full-length clone 16S rRNA sequences of OTUs detected more than once, based on 1,153 homologous positions filtered by base frequency (50\%) using MEGA6. Tag sequences that were identical to a clone sequence were identified. Bootstrap values were calculated in MEGA6, and nodes with >50\% support, based on 1,000 replicates are displayed. Haliangium tepidum (NR_024781) and Kofleria flava (NR_041981) were used as outgroups.

The dominance of Epsilonproteobacteria on surface basalt biofilms within the diffuse-flow region is consistent with previous observations showing that this group is commonly found at deep-sea hydrothermal vents, particularly in diffuse-flow vent fluids, microbial mats, and in association with macrofauna. As a group, Epsilonproteobacteria demonstrate a diverse range of physiologies. They are capable of oxidizing reduced sulfur compounds or hydrogen autotrophically or mixotrophically and can use oxygen, nitrate, or sulfur as electron acceptors.

They are believed to have important roles in the cycling of sulfur, nitrogen, and hydrogen at deep-sea hydrothermal vents (Longnecker and Reysenbach, 2001; Nakagawa et al., 2005; Takai et al., 2005; Sievert and Vetriani, 2012). In part, this broad range of metabolic activities allows Epsilonproteobacteria to colonize and proliferate in numerous vent environments (Campbell et al., 2006, 2013). Based on known metabolic activities of cultured representatives, it would appear that the earliest colonists (Arcobacter, Sulfurovum, Sulfurimonas,) are possible chemolithoautotrophs that might be reducing nitrate and/or oxygen and oxidizing reduced sulfur compounds and/or hydrogen (Campbell et al., 2006). Certain bacterial sequences (Clone.113 Tag.178) are closely related (>98\% similar) to a known sulfur-oxidizing chemolithoautotroph, Sulfurovum lithotrophicum (Inagaki et al., 2004). These putative autotrophic Epsilonproteobacteria are likely supplied in abundance from diffuse-flow vent fluids, both as particle-associated and freeliving populations originating in the sub-seafloor mixing zone of hydrothermal fluid and seawater (Huber et al., 2003, 2007;
Opatkiewicz et al., 2009; Sylvan et al., 2012a; Campbell et al., 2013). Autotrophic taxa capable of forming biofilms could settle out from vent fluids and rapidly colonize exposed surfaces. In this study, biofilms were visibly detected after only 4 days at both Tica (experimental panels) and Tamtown, indicating the rapid rate at which these microorganisms can establish high population densities.

Based on our full-length clone and V4 tag data, initial biofilms consisted of Arcobacter and Sulfurovum-like organisms. Other researchers have documented biofilms formed by filamentoussulfur producing bacteria belonging to the genus Arcobacter at different vent locations after only a few days (Taylor and Wirsen, 1997; Taylor et al., 1999; Wirsen et al., 2002; Moussard et al., 2006). Arcobacter species seem to grow optimally and selectively at high sulfide concentrations (Wirsen et al., 2002; Moussard et al., 2006; Sievert et al., 2007). Based on the pattern observed in this study and by others (Taylor et al., 1999; Moussard et al., 2006; Sievert et al., 2007, 2008), we propose that this genus specializes in rapid colonization ( $<4$ days), quickly utilizing available sulfide (Sievert et al., 2007). It is also possible that elemental sulfur formed by Arcobacter (Wirsen et al., 2002) serves as the substrate for other sulfur-oxidizing bacteria, such as Sulfurovum and Sulfurimonas (Pjevac et al., 2014). After $\sim 2$ weeks, Arcobacter species declined and were replaced, and possibly outcompeted, by Sulfurovum and other epsilonproteobacterial species with potentially more diverse metabolisms and/or different life strategies. The relatively high micro-diversity observed among Sulfurovum-related OTUs (31 
OTUs detected, clone and tag libraries) contrasts with the low diversity observed among the Arcobacter-related OTUs (seven OTUs detected, clone and tag libraries). Possibly, these co-inhabiting Sulfurovum phylotypes might be adapted to subtle differences in environmental parameters such as temperature or sulfide concentrations, and therefore able to fill multiple metabolic niches (Sievert and Vetriani, 2012). As a result, the elevated micro-diversity among Sulfurovumlike organisms might translate to greater metabolic diversity and greater competitive ability, leading to the decline of arcobacters.

Over time, the community dominated by putative chemoautotrophs changes to a community with an increased proportion of microbial groups with known heterotrophic representatives, i.e., Bacteroidetes, Delta- and Gammaproteobacteria and Sulfurospirillum. This increase in bacterial diversity with biofilm age is reflected in the Chaol richness indices and rarefaction curves, and can be seen for both experimental and control locations. With the exception of $9 \mathrm{C}$, the communities found on the youngest samples are characterized as being the least diverse and most uneven, while the opposite was true for the 9-months samples. Most likely, the initial colonization and growth by vent fluid-associated chemoautotrophs leads to an increased availability of organic matter and the establishment of complex, three-dimensional biofilm structures. A mature biofilm could accommodate additional niches and allow for the co-occurrence of a larger variety of metabolisms as the biofilm ages. Furthermore, this type of established biofilm would be able to support bacteria growing under a range of conditions, from aerobic to microaerophilic to anaerobic, and from autotrophic to mixotrophic and heterotrophic (Davey and O'toole, 2000; Stoodley et al., 2002). For example, sequences belonging to the family Desulfobulbaceae were not found until day 13 and were only detected above $1 \%$ after $\sim 2.5$ months $(76 \mathrm{E})$ at Tica and Tamtown $(\sim 5-8$ monthsold). Cultured representatives from this family are anaerobic, sulfate-reducing bacteria (Savage et al., 2010), which would be expected to thrive at later time points once a more mature biofilm with anaerobic conditions has developed.

In addition, the settlement and immigration of macrofaunal organisms onto the basalt surfaces would further increase microbial diversity by the introduction of macrofaunalassociated microbes and by further increasing possible niches available for microbes. We observed a substantial increase in colonizing macrofauna over time on the experimental panels. For example, at day 4, the experimental panel had five individual macrofaunal colonists; the day 76 experimental panel had 78 colonists, and the 9 months panel (day 293) hosted 122 colonists (Shank, unpublished data). The earliest colonists observed on these panels included foraminifera, and mobile limpets and polychaetes. In contrast, Tevnia jerichonana and Riftia pachyptila were not detected until 9 months. Interestingly, a gammaproteobacterial tag (Tag.92) sharing $99 \%$ sequence identity with the symbiont of Tevnia jerichonana (Nelson and Fisher, 2000) was detected prior to observed settlement of Tevnia jerichonana. This sequence could have come from the free-living form of the symbiont and may act as a settlement cue for larval Tevnia jerichonana recruits. Based on number of sequences detected on these diffuse-flow basalts that are close relatives of known vent symbionts, this environment could be a prime habitat for the free-living form of different symbionts (Harmer et al., 2008; Callac et al., 2013). However, we cannot exclude the possibility that recently settled Tevnia jerichonana recruits with incorporated symbionts were present, but not detected upon examination with the dissecting microscope.

We observed evidence of macrofaunal feeding upon welldeveloped biofilms on early experimental panels in the form of gastropod radula scrapping patterns (days 4 and 13; Supplementary Figure S1E). The grazing activity partially clears the associated biofilms, rejuvenating the biofilm by opening up new surfaces for re-colonization and thus increasing overall diversity, providing a possible mechanism to explain the differences observed among the panels.

\section{Microbial Succession: OTU Level Diversity}

Although the overall proportions of microbial groupings changed with time, we found the same OTUs at early and late time points, indicating that microbial phylotypes that settle or immigrate onto new surfaces within days of initial exposure can persist for months ( $>9$ months). Our results suggest that early settlers play a key role in determining the composition of the older community. Rather than a new set of OTUs supplanting the initial settlers, it appears that most OTUs establish themselves within days and, while abundances change with time, the overall OTU profile does not. This pattern persists for both the experimental and control locations, and for different classes. For example, $55 \%$ of the tag OTUs belonging to the genus Sulfurovum were found at both $9 \mathrm{E}$ and $293 \mathrm{E}$ (17/31) and these OTUs make up $>99 \%$ of all Sulfurovum tags. We hypothesize that the ability to form biofilms would help allow specific phylotypes (OTUs) to persist over time. The biofilm matrix, which is to a large extent composed of exopolymeric substances excreted by the biofilm-forming microbes, like exopolysaccharides (EPSs), offers protection from environmental variations, like $\mathrm{pH}$ and temperature, and can also decrease toxicity by binding and sequestering heavy metals contained in the hydrothermal fluid (Edwards et al., 2005; Sievert and Vetriani, 2012). Various Epsilonproteobacteria isolates, including Sulfurovum, are known to contain genes for biosynthesis of EPSs and for quorum sensing (Sievert and Vetriani, 2012; Pérez-Rodríguez et al., 2014). While Sulfurovum taxa were abundant and diverse throughout the experiment, they were especially abundant during the first 2 weeks, comprising $60-80 \%$ of each community, making them key players in establishing a persistent biofilm. Interestingly, the most numerically abundant OTU belongs within the genus Sulfurovum (Clone.32. Tag.264) and is highly similar ( $\geq 98 \%)$ to sequences recovered from other active sulfides and diffuse-flow vent sites (Stott et al., 2008; Zhou et al., 2009) and to sequences recovered from inactive sulfides on the EPR (Sylvan et al., 2012b). It is possible that this OTU represents a dominant, widely distributed vent-associated species that is prevalent at active vent sites and that persists at inactive sites by being able to oxidize sulfide minerals contained in the chimneys or, alternatively, its 
DNA might be preserved and thus could represent a 'relic' of past activity.

\section{Comparison among Vent Sites and of Pre-eruption with Post-eruption Environments}

From our results it is clear that, despite spatial and temporal separation, bacterial communities of similar ages, in similar habitats, are relatively comparable in community composition and distribution. Although separated by $\sim 0.58 \mathrm{~km}$ and sampled 19-28 months apart, bacterial communities from Tica vent and Tamtown [Basalt and 293E or 76E; Trap and 4E] share similar, but not identical, class and genus level phylogeny. The Trap sample is exclusively comprised of Epsilonproteobacteria (Arcobacter, Sulfurovum, and Sulfurimonas), and is similar in composition to day $4 \mathrm{E}$ at the experimental pre-eruption site. These samples share $>30 \%$ of the identified Epsilonproteobacterial OTUs, even though they were sampled at different times and locations and represent different substrate types [stainless-steel (Trap) and basalt (day 4E)], suggesting that, at least for early colonization, the material of the provided substrate does not appear to play a major role. The post-eruption Tamtown Basalt as well as the pre-eruption $293 \mathrm{E}$ and $76 \mathrm{E}$ are comprised of Sulfurovum, Bacteroidetes, Delta- and Gammaproteobacteria. The volcanic eruption has been dated around the end of 2005/early 2006, with brief pulses of activity still measured through April 2006 (Tolstoy et al., 2006; Soule et al., 2007). This provides a conservative estimate of the age of the Tamtown Basalt community of around 5-8 months, which is comparable in age to 293E. Comparing diversity estimates for these two communities, we find that 293E appears to host a substantially more diverse community than Tamtown Basalt. Most likely, more species immigrated onto the panel samples than the Tamtown Basalt, because they were placed in the midst of an active vent community, with a diverse and thriving macrofaunal community and associated microbes. In contrast, the Tamtown sample represents a natural basalt community obtained from an environment in which the entire community had been destroyed by the volcanic eruption months before. At the time of sampling, there were small tubeworms (Tevnia jerichonana; $\sim 2 \mathrm{~cm}$ in length) colonizing the Tamtown basalt, and Ctenopelta porifera limpets in the vicinity, but the macrofaunal community was young and not highly diverse (Nees et al., 2009). In contrast, the 293E experimental panel was colonized with multiple species of polychaetes and gastropods (Shank, unpublished data). The precise timing of when the diffuse-flow venting at Tamtown became active after the eruption is not known. Thus, the Tamtown biological community (native Basalt sample) could potentially be younger than initially estimated if venting did not start immediately after the eruption, thereby explaining why the native Basalt sample diversity estimates are more in line with the earlier panel samples. Still, the entire native Basalt community clusters with that of day $76 \mathrm{E}$ and day $293 \mathrm{E}$ rather than the earlier panels, suggesting that the site had at least been active for several months.

At the level of specific OTUs, there is extensive overlap, with almost all native Basalt OTUs also detected at the Tica vent site (95\% of the OTUs associated with the natural Basalt at Tamtown were also recovered in the experimental panels at Tica; only seven OTUs were exclusive to the native Basalt sample and these OTUs comprise $<2 \%$ of the total tags for the native Basalt sample). Although these sites are $0.58 \mathrm{~km}$ apart, it is possible they are supplied from connected sub-seafloor hydrothermal conduits with similar microbial communities. Additionally, the similar temperature and chemical regimes found in each diffuse-flow habitat may select for identical OTUs. The overlap in community composition, despite the spatial and temporal separation and the fact that the sampling involved both experimental panels and natural basalt communities, is remarkable, and suggests that the microbial communities colonizing new surfaces at diffuseflow vent sites might follow a predictable successional pattern, paralleling that observed for macrofauna (Shank et al., 1998). Further work is required, however, to confirm this intriguing hypothesis.

Although the Tamtown and Tica communities share many OTUs, they can be distinguished by disparate proportions of two phylogentic groups, Sulfurovum and Bacteroidetes. The native Basalt hosts a higher proportion of Sulfurovum (70\% versus $35 \%$ ), and the lower proportion of Bacteroidetes (13\% versus $20 \%$ ) than Tica panel day 293E. While microbial communities at both Tamtown and Tica were likely supported by a combination of chemosynthetic and heterotrophic processes, we propose that the Tamtown native Basalt microbial community was predominantly driven by chemosynthetic processes, while the Tica panel community (day 293E), set in an environment with abundant macrofauna and associated organic matter, was more influenced by heterotrophic processes.

\section{Comparison between Biofilm Communities and Diffuse-Flow Fluid Communities: Evidence for Species Sorting}

Previous studies have found varying degrees of geographical isolation among bacterial communities in diffuse-flow vent fluids and those associated with plume particles (Opatkiewicz et al., 2009; Huber et al., 2010; Sylvan et al., 2012a), both of which represent the source communities from which the biofilm community is recruited. Opatkiewicz et al. (2009) found considerable overlap in chemical parameters between different vents, yet each vent maintained a consistent and statistically distinct microbial community structure, as determined by TRFLP. One possible explanation for the different findings is that the sites in our study (Tica and Tamtown) had similar chemical parameters and biological indicators (temperatures between 10 and $30^{\circ} \mathrm{C}$ and presence of similar fauna, i.e., Tevnia jerichonana), and were separated by only $0.58 \mathrm{~km}$. Furthermore, Opatkiewicz et al. (2009), Huber et al. (2010), and Sylvan et al. (2012a) all studied the diversity of microbial communities found in diffuseflow fluids. It is possible that fluid-associated communities reflect the site-specific variations in subsurface diversity, while the selective pressure of establishing a microbial biofilm creates greater community overlap across neighboring sites by means of species sorting. Species sorting occurs when biotic and abiotic environmental conditions select for a subset of bacteria from a larger population, creating a community distinct from the source population (Leibold et al., 2004). Species sorting has been 
documented as an important biofilm assembly mechanism in fresh water streams (Besemer et al., 2012) and cold seeps (Zhang et al., 2014) among other locations, but has not been studied explicitly at diffuse-flow vent sites.

As further support for species sorting, clear differences between fluid and biofilm associated groups can be identified by comparing our results with published studies of vent fluids. Diffuse-flow fluids from Tica vent hosted abundant and diverse populations of Archaea, as well as gammaproteobacterial Oceanospirillales (Campbell et al., 2013), groups which were absent or detected at very low abundances $(<<1 \%)$ within the biofilms studied here. In our results, the most common gammaproteobacterial sequences on the 9-months panels belong within the Chromatiales, Methylococcales, Thiotrichales. Other researchers found Methylococcales and Thiotrichales tags to be the most common gammaproteobacterial sequences in vent associated mats (Crépeau et al., 2011; Forget and Juniper, 2013), in contrast to vent fluids where the gammaproteobacterial community is dominated by Pseudoalteromonas and Alteromonadales (Huber et al., 2007).

Surface-associated samples in this study had substantially lower overall diversity than the fluids investigated in other studies, even at Tica vent itself, with Chao-1 values one to two orders of magnitude lower [109-230 (tags:this study); 36,869 (Huber et al., 2007); 2468-4193 (EPR: (Campbell et al., 2013)]. Certainly, higher Chao-1 values can be expected with larger sample size and greater sequencing effort. Yet, intriguingly, even at the same vent location (Tica), when Campbell et al. (2013) winnowed their data to include only vent-specific bacterial, $16 \mathrm{~S}$ rDNA amplicons they still detected a substantially greater number of observed species $\left(\mathrm{N}_{\mathrm{obs}}: 305\right.$ this study, maximum $\mathrm{N}_{\mathrm{obs}}: 168$ at 293E) and obtained Chao-1 values higher than our surface-associated estimates (Chao-1:334 95\% CI:317-377); this study, Chao-1:230 (95\% CI:199-292). Based on our findings, we hypothesize that the process of biofilm formation, on basalt surfaces in diffuse-flow regions, functions as a means for species sorting by selecting for a subset of the fluid-associated microbial community and generating similar surface-associated communities between neighboring vent sites.

\section{Conclusion}

The results from this study contribute to our understanding of the composition and ecology of microbial biofilms in diffuseflow vent habitats. Not only did we document an increase in microbial diversity over short time scales, the transition from

\section{References}

Alain, K., Zbinden, M., Le Bris, N., Lesongeur, F., Quérellou, J., Gaill, F., et al. (2004). Early steps in microbial colonization processes at deep-sea hydrothermal vents. Environ. Microbiol. 6, 227-241. doi: 10.1111/j.14622920.2003.00557.x

Ashelford, K. E., Chuzhanova, N. A., Fry, J. C., Jones, A. J., and Weightman, A. J. (2006). New screening software shows that most recent large 16s rrna gene an early biofilm dominated by putative autotrophs to a more diverse late biofilm, but we also identified a pattern of shared OTUs over time and across different vent sites. We propose that the process of biofilm formation selects for a subset of the fluid-associated microbial community and generates similar surface-associated communities. Future studies are needed to address the functional aspects of these communities thereby elucidating the roles of the various phylogenetic groups in biofilm formation and maintenance, and to clarify if the observed micro-diversity, e.g., within the Sulfurovum and Bacteroidetes group, translates to metabolic and/or niche diversity. Indepth temporal studies will allow us to resolve the patterns of biofilm community development, how spatially separated communities are related, and to investigate the exact role of biofilms as a precursor to macrofaunal settlement and immigration.

\section{Acknowledgments}

This work was partly supported by grants from the US National Science Foundation to SS (OCE-0452333, 1136727), to TS (OCE-0117117, 0525907, 0961186, 1043064, 0327261, $1131620)$, to WS and KD (1434798), as well as a grant by the WHOI Deep Ocean Exploration Institute to SB, TS, and SS. We would like to thank the pilots, officers, and crew members of Atlantis/Alvin for their dedication and expertise, which made this study possible and without which the development and application of chemical sensor systems at deep-sea vents would not have been possible. We also thank the Chief Scientists of the following cruises for accommodating us: Feb 2004 AT11-7 (H. Schouten), April 2004 AT11-10 (R. Lutz), Nov 2004 AT11-20 (M. Lilley). We further thank Dan Fornari for providing the native basalt for the experimental surfaces, and guest student Melissa B. Duhaime for help with DNA extractions of the experimental panels in 2005. We gratefully acknowledge Karen L. Von Damm for providing early opportunities to test chemical sensor systems at EPR $9 \mathrm{~N}$, and helping with interpretation and integration of the electrochemical data with other chemical data that she had accumulated.

\section{Supplementary Material}

The Supplementary Material for this article can be found online at: http://journal.frontiersin.org/article/10.3389/fmicb. 2015.00901

clone libraries contain chimeras. Appl. Environ. Microbiol. 72, 5734-5741. doi: 10.1128/AEM.00556-06

Baross, J. A., and Hoffman, S. E. (1985). Submarine hydrothermal vents and associated gradient environments as sites for the origin and evolution of life. Orig. Life Evol. Biosph. 15, 327-345. doi: 10.1007/BF01808177

Besemer, K., Peter, H., Logue, J. B., Langenheder, S., Lindström, E. S., Tranvik, L. J., et al. (2012). Unraveling assembly of stream biofilm communities. ISME J. 6, 1459-1468. doi: 10.1038/ismej.2011.205 
Byrne, N., Lesongeur, F., Bienvenu, N., Geslin, C., Alain, K., Prieur, D., et al. (2009). Effect of variation of environmental conditions on the microbial communities of deep-sea vent chimneys, cultured in a bioreactor. Extremophiles 13, 595-608. doi: 10.1007/s00792-009-0242-6

Callac, N., Rommevaux-Jestin, C., Rouxel, O., Lesongeur, F., Liorzou, C., Bollinger, C., et al. (2013). Microbial colonization of basaltic glasses in hydrothermal organic-rich sediments at Guaymas Basin. Front. Microbiol. 4:250. doi: 10.3389/fmicb.2013.00250

Campbell, B. J., Engel, A. S., Porter, M. L., and Takai, K. (2006). The versatile $\varepsilon$-proteobacteria: key players in sulphidic habitats. Nat. Rev. Microbiol. 4, 458-468. doi: 10.1038/nrmicro1414

Campbell, B. J., Polson, S. W., Allen, L. Z., Williamson, S. J., Lee, C. K., Wommack, K. E., et al. (2013). Diffuse flow environments within basalt- and sediment-based hydrothermal vent ecosystems harbor specialized microbial communities. Front. Microbiol. 4:182. doi: 10.3389/fmicb.2013.00182

Caporaso, J. G., Kuczynski, J., Stombaugh, J., Bittinger, K., Bushman, F. D., Costello, E. K., et al. (2010). QIIME allows analysis of highthroughput community sequencing data. Nat. Methods 7, 335-336. doi: 10.1038/nmeth.f.303

Cowen, J. P., Glazer, B., Fornari, D. J., Shank, T. M., Soule, S. A., Love, B., et al. (2007). Volcanic eruptions at East Pacific Rise near $9^{\circ} 50^{\prime}$ N. EOS 88, 81-83. doi: 10.1029/2007EO070001

Crépeau, V., Cambon-Bonavita, M.-A., Lesongeur, F., Randrianalivelo, H., Sarradin, P. M., Sarrazin, J., et al. (2011). Diversity and function in microbial mats from the Lucky Strike hydrothermal vent field. FEMS Microbiol. Ecol. 76, 524-540. doi: 10.1111/j.1574-6941.2011.01070.x

Davey, M. E., and O'toole, G. A. (2000). Microbial biofilms: from ecology to molecular genetics. Microbiol. Mol. Biol. Rev. 64, 847-867. doi: 10.1128/MMBR.64.4.847-867.2000

Delaney, J. R., Kelley, D. S., Lilley, M. D., Butterfield, D. A., Baross, J. A., Wilcock, W. S. D., et al. (1998). The quantum event of oceanic crustal accretion: impacts of diking at mid-ocean ridges. Science 281, 222-230. doi: $10.1126 /$ science.281.5374.222

Edwards, K. J., Bach, W., and McCollom, T. M. (2005). Geomicrobiology in oceanography: microbe-mineral interactions at and below the seafloor. Trends Microbiol. 13, 449-456. doi: 10.1016/j.tim.2005.07.005

Embley, R. W., Chadwick, W. W., Jonasson, I. R., Butterfield, D. A., and Baker, E. T. (1995). Initial results of the rapid response to the 1993 CoAxial event: relationships between hydrothermal and volcanic processes. Geophys. Res. Lett. 22, 143-146. doi: 10.1029/94GL02281

Forget, N. L., and Juniper, S. K. (2013). Free-living bacterial communities associated with tubeworm (Ridgeia piscesae) aggregations in contrasting diffuse flow hydrothermal vent habitats at the Main Endeavour Field, Juan de Fuca Ridge. Microbiologyopen 2, 259-275. doi: 10.1002/mbo3.70

Forget, N. L., Murdock, S. A., and Juniper, S. K. (2010). Bacterial diversity in Ferich hydrothermal sediments at two South Tonga Arc submarine volcanoes. Geobiology 8, 417-432. doi: 10.1111/j.1472-4669.2010.00247.x

Goffredi, S. K., Jones, W. J., Erhlich, H., Springer, A., and Vrijenhoek, R. C. (2008). Epibiotic bacteria associated with the recently discovered Yeti crab, Kiwa hirsuta. Environ. Microbiol. 10, 2623-2634. doi: 10.1111/j.14622920.2008.01684.x

Guezennec, J., Ortega Morales, O., Raguenes, G., and Geesey, G. (1998). Bacterial colonization of artificial substrate in the vicinity of deep-sea hydrothermal vents. FEMS Microbiol. Ecol. 26, 89-99. doi: 10.1111/j.15746941.1998.tb00495.x

Hadfield, M. G. (2011). Biofilms and marine invertebrate larvae: what bacteria produce that larvae use to choose settlement sites. Ann. Rev. Mar. Sci. 3, 453-470. doi: 10.1146/annurev-marine-120709-142753

Harmer, T. L., Rotjan, R. D., Nussbaumer, A. D., Bright, M., Ng, A. W., DeChaine, E. G., et al. (2008). Free-living tube worm endosymbionts found at deepsea vents. Appl. Environ. Microbiol. 74, 3895-3898. doi: 10.1128/AEM.02 470-07

Haymon, R. M., Fornari, D. J., Damm Von, K. L., Lilley, M. D., Perfit, M. R., Edmond, J. M., et al. (1993). Volcanic eruption of the mid-ocean ridge along the East Pacific Rise crest at $9^{\circ} 45-52^{\prime} \mathrm{N}$ : direct submersible observations of seafloor phenomena associated with an eruption event in April, 1991. Earth Planet. Sci. Lett. 119, 85-101. doi: 10.1016/0012-821X(93)9 0008-W
Huber, J. A., Butterfield, D. A., and Baross, J. A. (2003). Bacterial diversity in a subseafloor habitat following a deep-sea volcanic eruption. FEMS Microbiol. Ecol. 43, 393-409. doi: 10.1111/j.1574-6941.2003.tb01080.x

Huber, J. A., Cantin, H. V., Huse, S. M., Mark Welch, D. B., Sogin, M. L., and Butterfield, D. A. (2010). Isolated communities of Epsilonproteobacteria in hydrothermal vent fluids of the Mariana Arc seamounts. FEMS Microbiol. Ecol. 73, 538-549. doi: 10.1111/j.1574-6941.2010.00910.x

Huber, J. A., Johnson, H. P., Butterfield, D. A., and Baross, J. A. (2006). Microbial life in ridge flank crustal fluids. Environ. Microbiol. 8, 88-99. doi: 10.1111/j.1462-2920.2005.00872.x

Huber, J. A., Mark Welch, D. B., Morrison, H. G., Huse, S. M., Neal, P. R., Butterfield, D. A., et al. (2007). Microbial population structures in the deep marine biosphere. Science 318, 97-100. doi: 10.1126/science.1146689

Huber, T., Faulkner, G., and Hugenholtz, P. (2004). Bellerophon: a program to detect chimeric sequences in multiple sequence alignments. Bioinformatics 20, 2317-2319. doi: 10.1093/bioinformatics/bth226

Inagaki, F., Takai, K., Nealson, K. H., and Horikoshi, K. (2004). Sulfurovum lithotrophicum gen. nov., sp. nov., a novel sulfur-oxidizing chemolithoautotroph within the $\varepsilon$-Proteobacteria isolated from Okinawa Trough hydrothermal sediments. Int. J. Syst. Evol. Microbiol. 54, 1477-1482. doi: 10.1099/ijs.0.03042-0

Jannasch, H. W., and Mottl, M. J. (1985). Geomicrobiology of deep-sea hydrothermal vents. Science 229, 717-725. doi: 10.1126/science.229.4715.717

Kirchman, D. L. (2002). The ecology of Cytophaga-Flavobacteria in aquatic environments. FEMS Microbiol. Ecol. 39, 91-100. doi: 10.1111/j.15746941.2002.tb00910.x

Leibold, M. A., Holyoak, M., Mouquet, N., Amarasekare, P., Chase, J. M., Hoopes, M. F., et al. (2004). The metacommunity concept: a framework for multi-scale community ecology. Ecol. Lett. 7, 601-613. doi: 10.1111/j.14610248.2004.00608.x

Li, Y. F., Guo, X. P., Yang, J. L., Liang, X., Bao, W. Y., Shen, P. J., et al. (2014). Effects of bacterial biofilms on settlement of plantigrades of the mussel Mytilus coruscus. Aquaculture 433, 434-441. doi: 10.1016/j.aquaculture.2014.06.031

Longnecker, K., and Reysenbach, A. L. (2001). Expansion of the geographic distribution of a novel lineage of $\varepsilon$-Proteobacteria to a hydrothermal vent site on the Southern East Pacific Rise. FEMS Microbiol. Ecol. 35, 287-293. doi: 10.1111/j.1574-6941.2001.tb00814.x

Lozupone, C., Lladser, M. E., Knights, D., Stombaugh, J., and Knight, R. (2010). UniFrac: an effective distance metric for microbial community comparison. ISME J. 5, 169-172. doi: 10.1038/ismej.2010.133

Lutz, R. A., and Kennish, M. J. (1993). Ecology of deep-sea hydrothermal vent communities: a review. Rev. Geophys. 31, 211-242. doi: 10.1029/93RG01280

Moussard, H., Corre, E., Cambon-Bonavita, M.-A., Fouquet, Y., and Jeanthon, C. (2006). Novel uncultured Epsilonproteobacteria dominate a filamentous sulphur mat from the $13^{\circ} \mathrm{N}$ hydrothermal vent field, East Pacific Rise. FEMS Microbiol. Ecol. 58, 449-463. doi: 10.1111/j.1574-6941.2006.00192.x

Nakagawa, S., and Takai, K. (2008). Deep-sea vent chemoautotrophs: diversity, biochemistry and ecological significance. FEMS Microbiol. Ecol. 65, 1-14. doi: 10.1111/j.1574-6941.2008.00502.x

Nakagawa, S., Takai, K., Inagaki, F., Hirayama, H., Nunoura, T., Horikoshi, K., et al. (2005). Distribution, phylogenetic diversity and physiological characteristics of epsilon-Proteobacteria in a deep-sea hydrothermal field. Environ. Microbiol. 7, 1619-1632. doi: 10.1111/j.1462-2920.2005.00856.x

Nees, H. A., Lutz, R. A., Shank, T. M., and Luther, G. W. (2009). Pre- and posteruption diffuse flow variability among tubeworm habitats at $9^{\circ} 50^{\prime}$ north on the East Pacific Rise. Deep Sea Res. Part 2 Top. Stud. Oceanogr. 56, 1607-1615. doi: 10.1016/j.dsr2.2009.05.007

Nelson, K., and Fisher, C. R. (2000). Absence of cospeciation in deep-sea vestimentiferan tube worms and their bacterial endosymbionts. Symbiosis 28, $1-15$.

Opatkiewicz, A. D., Butterfield, D. A., and Baross, J. A. (2009). Individual hydrothermal vents at Axial Seamount harbor distinct subseafloor microbial communities. FEMS Microbiol. Ecol. 70, 413-424. doi: 10.1111/j.15746941.2009.00747.x

Pérez-Rodríguez, I., Bolognini, M., Ricci, J., Bini, E., and Vetriani, C. (2014). From deep-sea volcanoes to human pathogens: a conserved quorum-sensing signal in Epsilonproteobacteria. ISME J. 9, 1222-1234. doi: 10.1038/ismej.20 14.214 
Pjevac, P., Kamyshny, A., Dyksma, S., and Mußmann, M. (2014). Microbial consumption of zero-valence sulfur in marine benthic habitats. Environ. Microbiol. 16, 3416-3430. doi: 10.1111/1462-2920.12410

Polz, M. F., and Cavanaugh, C. M. (1998). Bias in template-to-product ratios in multitemplate PCR. Appl. Environ. Microbiol. 64, 3724-3730. doi: 10.1146/annurev.bi.61.070192.001023

Rittschof, D., Forward, R. B. Jr., Cannon, G., Welch, J. M., McClary, M. Jr., Holm, E. R., et al. (1998). Cues and context: larval responses to physical and chemical cues. Biofouling 12, 31-44. doi: 10.1080/08927019809378344

Rubin, K. H., Perfit, M. R., Fornari, D. J., Soule, S. A., Tolstoy, M., and Waldhauser, F. (2006). Geochronology and composition of the 2005-06 volcanic eruptions of the East Pacific Rise, $9^{\circ} 46^{\prime}-56^{\prime}$ N. Eos. Trans. AGU 87, Fall Meet. Suppl., Abstract V23B-0602.

Santelli, C. M., Edgcomb, V. P., Bach, W., and Edwards, K. J. (2009). The diversity and abundance of bacteria inhabiting seafloor lavas positively correlate with rock alteration. Environ. Microbiol. 11, 86-98. doi: 10.1111/j.14622920.2008.01743.x

Santelli, C. M., Orcutt, B. N., Banning, E., Bach, W., Moyer, C. L., Sogin, M. L., et al. (2008). Abundance and diversity of microbial life in ocean crust. Nature 453, 653-656. doi: 10.1038/nature06899

Savage, K. N., Krumholz, L. R., Gieg, L. M., Parisi, V. A., Suflita, J. M., Allen, J., et al. (2010). Biodegradation of low-molecular-weight alkanes under mesophilic, sulfate-reducing conditions: metabolic intermediates and community patterns. FEMS Microbiol. Ecol. 72, 485-495. doi: 10.1111/j.1574-6941.2010.00866.x

Shank, T. M., Fornari, D. J., Damm Von, K. L., Lilley, M. D., Haymon, R. M., and Lutz, R. A. (1998). Temporal and spatial patterns of biological community development at nascent deep-sea hydrothermal vents $\left(9^{\circ} 50^{\prime} \mathrm{N}\right.$, East Pacific Rise). Deep Sea Res. Part 1 Top. Stud. Oceanogr. 45, 465-515. doi: 10.1016/S0967-0645(97)00089-1

Sievert, S. M., Hügler, M., Wirsen, C. O., and Taylor, C. D. (2008). "Sulfur oxidation at deep-sea hydrothermal vents," in Microbial Sulfur Metabolism, eds C. Dahl and C. G. Friedrich (Berlin: Springer), 238-258.

Sievert, S., and Vetriani, C. (2012). Chemoautotrophy at deep-sea vents: past, present, and future. Oceanography 25, 218-233. doi: 10.5670/oceanog.2012.21

Sievert, S. M., Wieringa, E. B. A., Wirsen, C. O., and Taylor, C. D. (2007). Growth and mechanism of filamentous-sulfur formation by Candidatus Arcobacter sulfidicus in opposing oxygen-sulfide gradients. Environ. Microbiol. 9, 271-276. doi: 10.1111/j.1462-2920.2006.01156.x

Soule, S. A., Fornari, D. J., Perfit, M. R., and Rubin, K. H. (2007). New insights into mid-ocean ridge volcanic processes from the 2005-2006 eruption of the East Pacific Rise, $9^{\circ} 46^{\prime}$ N-9 $9^{\circ} 56^{\prime}$ N. Geology 35, 1079-1082. doi: 10.1130/G23924A.1

Stoodley, P., Sauer, K., Davies, K. G., and Costerton, J. W. (2002). Biofilms as complex differentiated communities. Annu. Rev. Microbiol. 56, 187-209. doi: 10.1146/annurev.micro.56.012302.160705

Stott, M. B., Saito, J. A., Crowe, M. A., Dunfield, P. F., Hou, S., Nakasone, E., et al. (2008). Culture-independent characterization of a novel microbial community at a hydrothermal vent at Brothers volcano, Kermadec arc, New Zealand. J. Geophys. Res. 113, B08. doi: 10.1029/2007JB005477

Sylvan, J. B., Pyenson, B. C., Rouxel, O., German, C. R., and Edwards, K. J. (2012a). Time-series analysis of two hydrothermal plumes at $9^{\circ} 50^{\prime} \mathrm{N}$ East Pacific Rise reveals distinct, heterogeneous bacterial populations. Geobiology 10, 178-192. doi: 10.1111/j.1472-4669.2011.00315.x

Sylvan, J. B., Toner, B. M., and Edwards, K. J. (2012b). Life and death of deep-sea vents: bacterial diversity and ecosystem succession on inactive hydrothermal sulfides. MBio 3, e00279-11. doi: 10.1128/mBio.00279-11
Takai, K., Campbell, B. J., Cary, S. C., Suzuki, M., Oida, H., Nunoura, T., et al. (2005). Enzymatic and genetic characterization of carbon and energy metabolisms by deep-sea hydrothermal chemolithoautotrophic isolates of Epsilonproteobacteria. Appl. Environ. Microbiol. 71, 7310-7320. doi: 10.1128/AEM.71.11.7310-7320.2005

Takai, K., Nakagawa, S., and Reysenbach, A. L. (2006). Microbial ecology of mid-ocean ridges and back-arc basins. Geophys. Monogr. 166, 185-213. doi: 10.1002/9781118666180.ch9

Tamura, K., Stecher, G., Peterson, D., Filipski, A., and Kumar, S. (2013). MEGA6: molecular evolutionary genetics analysis version 6.0. Mol. Biol. Evol. 30, 27252729. doi: 10.1093/molbev/mst197

Taylor, C. D., and Wirsen, C. O. (1997). Microbiology and ecology of filamentous sulfur formation. Science 277, 1483-1485. doi: 10.1126/science.277.5331. 1483

Taylor, C. D., Wirsen, C. O., and Gaill, F. (1999). Rapid microbial production of filamentous sulfur mats at hydrothermal vents. Appl. Environ. Microbiol. 65, 2253-2255. doi: 10.1007/BF00248960

Templeton, A. S., Knowles, E. J., Eldridge, D. L., Arey, B. W., Dohnalkova, A. C., Webb, S. M., et al. (2009). A seafloor microbial biome hosted within incipient ferromanganese crusts. Nat. Geosci. 2, 872-876. doi: 10.1038/ngeo696

Thompson, J. R., Marcelino, L. A., and Polz, M. F. (2002). Heteroduplexes in mixed-template amplifications: formation, consequence and elimination by “reconditioning PCR.". Nucleic Acids Res. 30, 2083-2088. doi: 10.1093/nar/30.9.2083

Tolstoy, M., Cowen, J. P., Baker, E. T., Fornari, D. J., Rubin, K. H., Shank, T. M., et al. (2006). A sea-floor spreading event captured by seismometers. Science 314, 1920-1922. doi: 10.1126/science. 1133950

Wahl, M., Goecke, F., Labes, A., Dobretsov, S., and Weinberger, F. (2012). The second skin: ecological role of epibiotic biofilms on marine organisms. Front. Microbiol. 3:292. doi: 10.3389/fmicb.2012.00292

Wieczorek, S. K., and Todd, C. D. (1998). Inhibition and facilitation of settlement of epifaunal marine invertebrate larvae by microbial biofilm cues. Biofouling 12, 81-118. doi: 10.1080/08927019809378348

Wirsen, C. O., Sievert, S. M., Cavanaugh, C. M., Molyneaux, S. J., Ahmad, A., Taylor, L. T., et al. (2002). Characterization of an autotrophic sulfide-oxidizing marine Arcobacter sp. that produces filamentous sulfur. Appl. Environ. Microbiol. 68, 316-325. doi: 10.1128/AEM.68.1.316-325.2002

Zhang, W. P., Wang, Y., Tian, R. M., Bougouffa, S., Yang, B., Cao, H. L., et al. (2014). Species sorting during biofilm assembly by artificial substrates deployed in a cold seep system. Sci. Rep. 4, 6647-6647. doi: 10.1038/srep06647

Zhou, H., Li, J., Peng, X., Meng, J., Wang, F., and Ai, Y. (2009). Microbial diversity of a sulfide black smoker in main endeavour hydrothermal vent field, Juan de Fuca Ridge. J. Microbiol. 47, 235-247. doi: 10.1007/s12275-008-0311-z

Conflict of Interest Statement: The authors declare that the research was conducted in the absence of any commercial or financial relationships that could be construed as a potential conflict of interest.

Copyright (c) 2015 Gulmann, Beaulieu, Shank, Ding, Seyfried and Sievert. This is an open-access article distributed under the terms of the Creative Commons Attribution License (CC BY). The use, distribution or reproduction in other forums is permitted, provided the original author(s) or licensor are credited and that the original publication in this journal is cited, in accordance with accepted academic practice. No use, distribution or reproduction is permitted which does not comply with these terms. 